\title{
Postsynaptic Dorsal Column Pathway of the Rat. III. Distribution of Ascending Afferent Fibers
}

\author{
Kenneth D. Cliffera and Glenn J. Giesler, Jr. \\ Department of Cell Biology and Neuroanatomy, University of Minnesota, Minneapolis, Minnesota 55455
}

\begin{abstract}
The distribution in the dorsal column nuclei (DCn) of postsynaptic dorsal column (PSDC) fibers was examined in rats following injections of Phaseolus vulgaris leucoagglutinin (PHA-L) in the spinal cord. Lemniscal neurons in the DCn were retrogradely labeled in the same animals by injecting the thalamus with Fluoro-Gold. In some experiments, primary afferent fibers were also labeled by injecting dorsal root ganglia with choleragenoid-conjugated HRP. Injections of PHA- $L$ into the cervical enlargement labeled many fibers and varicosities throughout most of the ipsilateral cuneate nucleus. Labeled fibers were also present in the external cuneate and internal basilar nuclei. Injections of PHA-L into thoracic cord labeled fibers and varicosities in the medial cuneate and lateral gracile nuclei, as well as the external cuneate nucleus. Injections into the lumbar enlargement labeled fibers and varicosities throughout most of the gracile nucleus. Injections in sacral cord labeled fibers in the most medial part of the gracile nucleus. Dense labeling of PSDC fibers was found in areas with high densities of retrogradely labeled lemniscal neurons and areas with high densities of primary afferent fibers. In all regions of the $\mathrm{DCn}$ and in the external cuneate nucleus, fibers and varicosities labeled for PHA-L were seen in apposition to retrogradely labeled lemniscal cells. The distribution of postsynaptic afferent fibers in the DCn of the rat and its relationship to lemniscal neurons and primary afferent fibers contrast sharply with these features in cats.
\end{abstract}

The dorsal column nuclei (DCn) were traditionally considered to receive somatosensory input solely from primary afferent fibers that ascend in the dorsal columns. More recently, evidence has accumulated that the $\mathrm{DCn}$ also receive important input through the dorsal columns from a large number of neurons located throughout the length of the ipsilateral dorsal horn of the spinal cord (Uddenberg, 1966, 1968a, b; Petit, 1972; Rustioni, 1973, 1974, 1976; Angaut-Petit, 1975a, b; Rustioni and Kaufman, 1977; Rustioni et al., 1979; Bennett et al., 1983, 1984;

\footnotetext{
Received Sep. 1, 1988; revised Nov. 28, 1988; accepted Dec. 22, 1988.

Supported by Grants BNS84187878, NS25932, and DA03981, and by a Doc toral Dissertation Special Grant to K.D.C. from the Graduate School of the University of Minnesota. K.D.C. was supported in part by training grant DA07234 We are grateful to Ms. C. Andersen and Mr. H. Troung for technical assistance, to Mr. G. Sedgewick for his excellent photographic assistance, and to Drs. P. Letourneau and $M$. Wessendorf for critically reading the manuscript.

Correspondence should be addressed to Glenn J. Giesler, Jr., Department of Cell Biology and Neuroanatomy, University of Minnesota, 4-135 Jackson Hall, 321 Church St. S. E., Minneapolis, MN 55455.

- Present address: Marine Biomedical Institute, The University of Texas Medical Branch, 200 University Blvd., Galveston, TX 77550.

Copyright (c) 1989 Society for Neuroscience $0270-6474 / 89 / 093146-23 \$ 02.00 / 0$
}

Lu et al., 1983; Giesler et al., 1984; Kamogawa and Bennett, 1986). Because these dorsal horn neurons are postsynaptic to primary afferent fibers, the term postsynaptic dorsal column neurons has been frequently used to describe them. The cells of origin of the postsynaptic dorsal column (PSDC) pathway in cats have been shown to transmit nociceptive information (Uddenberg, 1966, 1968b; Petit, 1972; Angaut-Petit, 1975b; Lu et al., 1983; Bennett et al., 1984; Kamogawa and Bennett, 1986). In addition, nociceptive responses have been recorded in the portion of the DCn of cats that receives PSDC input (Dart and Gordon, 1973; Angaut-Petit, 1975b). Postsynaptic afferent fibers appear to terminate exclusively in the rostral and ventral regions of the DCn in cats, avoiding the "cell cluster" regions of both nuclei (Rustioni, 1973, 1974). The cell cluster regions in cats contain the highest concentrations of both primary afferent projections (Hand, 1966; Rustioni and Macchi, 1968; Keller and Hand, 1970) and neurons that project to the thalamus (Berkley, 1975; Cheek et al., 1975; Blomqvist and Westman, 1975; Blomqvist, 1980; Bull and Berkley, 1984).

Some potentially important differences in the PSDC pathway between cats and rats have been noted. The neurons of origin of the PSDC pathway in rats are located more superficially in nucleus proprius of the spinal cord than are those of cats (Bennett et al., 1983; Giesler et al., 1984). Consistent with their position in the dorsal horn and in contrast to PSDC cells in cats, very few in rats receive a discernable input from nociceptors (Giesler and Cliffer, 1985). In light of these previously observed differences, we have examined the distribution of postsynaptic afferent fibers in the DCn of rats.

\section{Materials and Methods}

Male Sprague-Dawley rats, between 280 and 470 gm, (Biolab Corp., St. Paul, MN) were deeply anesthetized with sodium pentobarbital and placed in a stereotaxic apparatus. Supplementary injections of sodium pentobarbital or Brevital (sodium methohexital) were used to maintain anesthesia. Following laminectomy, a $2.5 \%$ solution of Phaseolus vulgaris leucoagglutinin (PHA-L; Gerfen and Sawchenko, 1984) in sodium PBS (pH, 7.2) was iontophoretically applied with multiple injections through a glass micropipette with a tip of $10-15 \mu \mathrm{m}(5 \mu \mathrm{A}$ for a total of $40 \mu \mathrm{A}$-min each injection, pulsed $8 \mathrm{sec}$ on, $2 \mathrm{sec}$ off). In most cases, 3-6 injections were confined to a single transverse plane. In some cases, 2-4 planes were injected, with up to 10 injections/plane. The illustrated cases injected in cervical or lumbar cord each received a total of 4-8 injections in 1 or 2 planes.

Four days prior to perfusion, a $2 \%$ solution of Fluoro-Gold (Schmued and Fallon, 1986) was injected into the contralateral thalamus. The animal was again anesthetized and placed in a stereotaxic apparatus. The skull was opened and a series of 10 injections of about $0.1 \mu \mathrm{l} \mathrm{each}$ were made in 2 planes through a $5 \mu$ l Hamilton syringe into the ventrobasal complex (VBC).

In some animals in which both PHA-L and Fluoro-Gold had been injected, and in others that had received only Fluoro-Gold, $0.2 \%$ chol- 
eragenoid-conjugated HRP (B-HRP; List Biological Laboratories, Inc., Campbell, CA) was injected into a dorsal root ganglion (DRG) 2 or 3 d prior to perfusion (for cervical or lumbar injections, respectively). The DRG of the spinal segment in which PHA-L had been injected was exposed and injections totaling about $1 \mu \mathrm{l}$ were made through a glass micropipette (tip diameter, $10-50 \mu \mathrm{m}$ ) attached to a $5 \mu \mathrm{l}$ Hamilton syringe. During these injections B-HRP that leaked out of the injection site was absorbed by a cotton wick. Adjacent DRGs were examined after processing to verify that neurons in them were not labeled. Results from cases in which there was diffuse labeling of the edge of the spinal cord or brain beyond the immediate vicinity of the injection were not used. Six cases were satisfactorily labeled with both PHA-L and B-HRP. Three cases labeled only with B-HRP were used for comparison with those labeled with PHA-L.

After survival periods of up to $41 \mathrm{~d}$ after injection of PHA-L, animals were deeply anesthetized with sodium pentobarbital and perfused with cold oxygenated calcium-free Tyrodes solution, followed by $4 \%$ paraformaldehyde $(\mathrm{pH}, 6.5)$, then $4 \%$ paraformaldehyde with $0.05 \%$ glutaraldehyde (pH, 9.4; Berod et al., 1981). Satisfactory survival times were determined to be approximately $14 \mathrm{~d}$ for injections in the cervical enlargement, and $35 \mathrm{~d}$ for injections in the lumbar enlargement. Tissue to be stained immunohistochemically for PHA-L only was postfixed $12-24 \mathrm{hr}$ in the high-pH fixative solution. Tissue to be reacted for HRP was not postfixed for more than $4 \mathrm{hr}$. After postfixation, tissue was stored in $10 \%$ sucrose in Sorenson's phosphate buffer $(\mathrm{pH}, 7.2)$.

The medulla and spinal cord were cut at $20 \mu \mathrm{m}$ on a freezing microtome in either the horizontal or transverse plane. Sections taken at intervals up to $100 \mu \mathrm{m}$ were placed in PBS for immunohistochemical staining for PHA-L. In cases in which B-HRP was injected, adjacent sections were placed in either distilled water or $0.2 \mathrm{M}$ phosphate buffer for TMB staining (Mesulam, 1978; Gibson et al., 1984).

PHA-L was immunohistochemically labeled using the avidin-biotin fluorescence technique. Goat anti-PHA-L (Vector Laboratories, Inc., Burlingame, CA) was applied at a dilution of $1 / 1000$ with $2 \%$ normal rabbit serum (NRS) overnight at $4^{\circ} \mathrm{C}$. Subsequent steps were performed at room temperature. Biotinylated rabbit anti-goat $\mathrm{IgG}$ (Vector) was applied for $1 \mathrm{hr}$ at $1 / 200$ dilution with $2 \%$ NRS. Fluorescein-conjugatedavidin (cell sorter grade; Vector) was applied for $1 \mathrm{hr}$ at a dilution of $1 / 100$. In some cases indirect fluorescent labeling was done using a dilution of $1 / 200$ for the primary antibody and fluorescein-conjugated swine anti-goat IgG (Tago, Inc., Burlingame, CA), diluted at 1/10. After mounting, immunohistochemically stained sections were counterstained with ethidium bromide (Schmued et al., 1982).

Fluorescent material was examined microscopically using reflected illumination. Double-exposed photomicrographs of fluorescein-labeled fibers and Fluoro-Gold-labeled cells were made using a $560 \mathrm{~nm}$ shortpass barrier filter and a $590 \mathrm{~nm}$ long-pass barrier filter, respectively, to enhance color contrast. TMB-stained HRP was viewed with dark-field illumination; contrast was enhanced using magenta filters. Dark-field illumination was used to determine architectonic boundaries. Drawings were made using a camera lucida drawing attachment on the microscope, with a $20 x$ objective. Borders and retrogradely labeled cells were drawn using colored paint pens and the drawings were photographed with filters to produce gray tones.

\section{Results}

\section{Fluoro-Gold}

A representative injection of Fluoro-Gold into the thalamus is illustrated in Figure 1; all such injections were similar. They extensively involved the ventrobasal, posterior thalamic and lateral geniculate nuclei $(B)$. Rostrally, injections extended into the laterodorsal thalamic nucleus $(A)$, and caudally into the medial geniculate nucleus (at a level not illustrated) and the rostral ventrolateral midbrain $(C)$. The injections involved the pretectal area $(B)$ and, in the midbrain, substantia nigra $(C)$. The most rostral part of the ventrobasal complex was not sub-

Figure I. Photomicrographs of an injection of Fluoro-Gold into the thalamus. $A-C$, Rostral to caudal. Asterisks, Third ventricle $(B)$; cerebral aqueduct $(C)$. Abbreviations: $C G$, central gray; $C P$, cerebral peduncle; $F$, fornix, $F R$, fasciculus retroflexus; $H n$, habenular nuclei; $H y$, hypo-
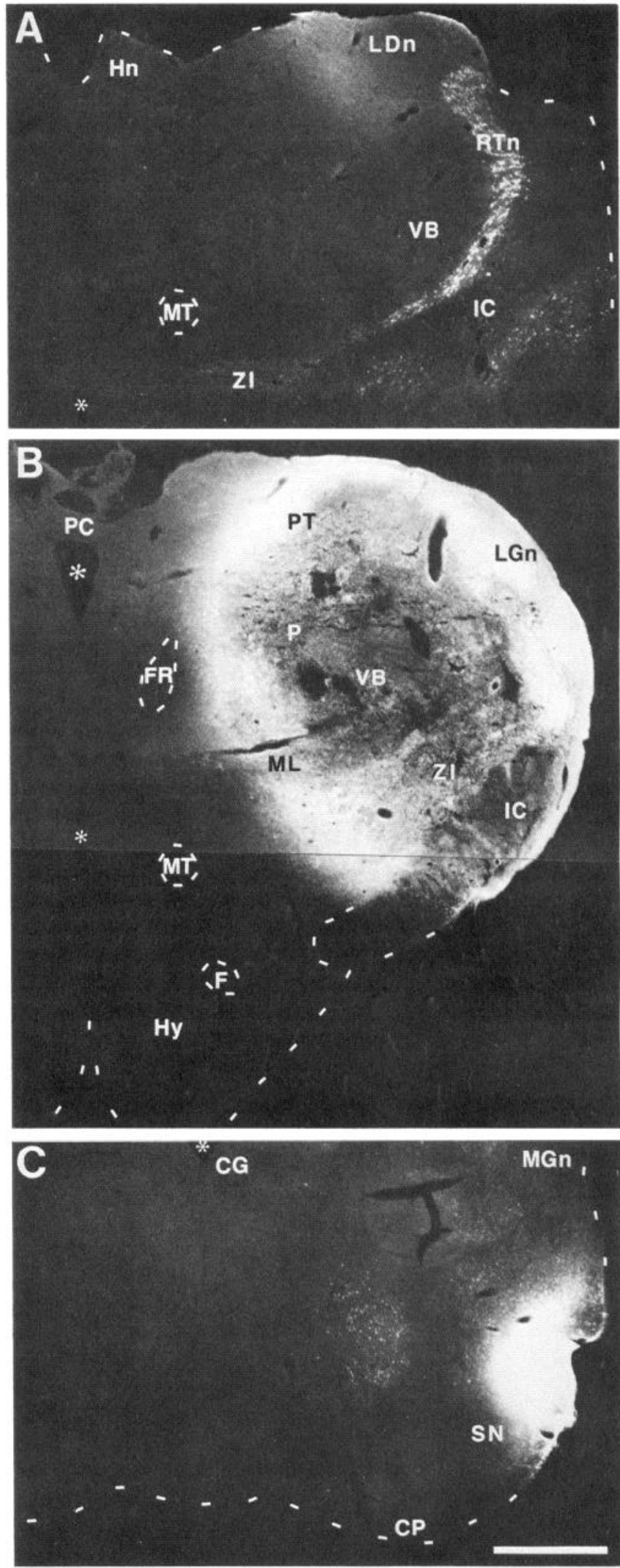

thalamus; $I C$, internal capsule; $L D n$, laterodorsal nucleus of the thalamus; $L G n$, lateral geniculate nucleus; $M G n$, medial geniculate nucleus; $M L$, medial lemniscus; $M T$, mammillothalamic tract; $P$, posterior nucleus of thalamus; $P C$, posterior commissure; $P T$, pretectal nuclei; $R T n$, reticular nucleus of the thalamus; $S N$, substantia nigra; $V B$, ventrobasal nuclei of the thalamus; $Z I$, zona incerta. Scale bar, $1 \mathrm{~mm}$. 

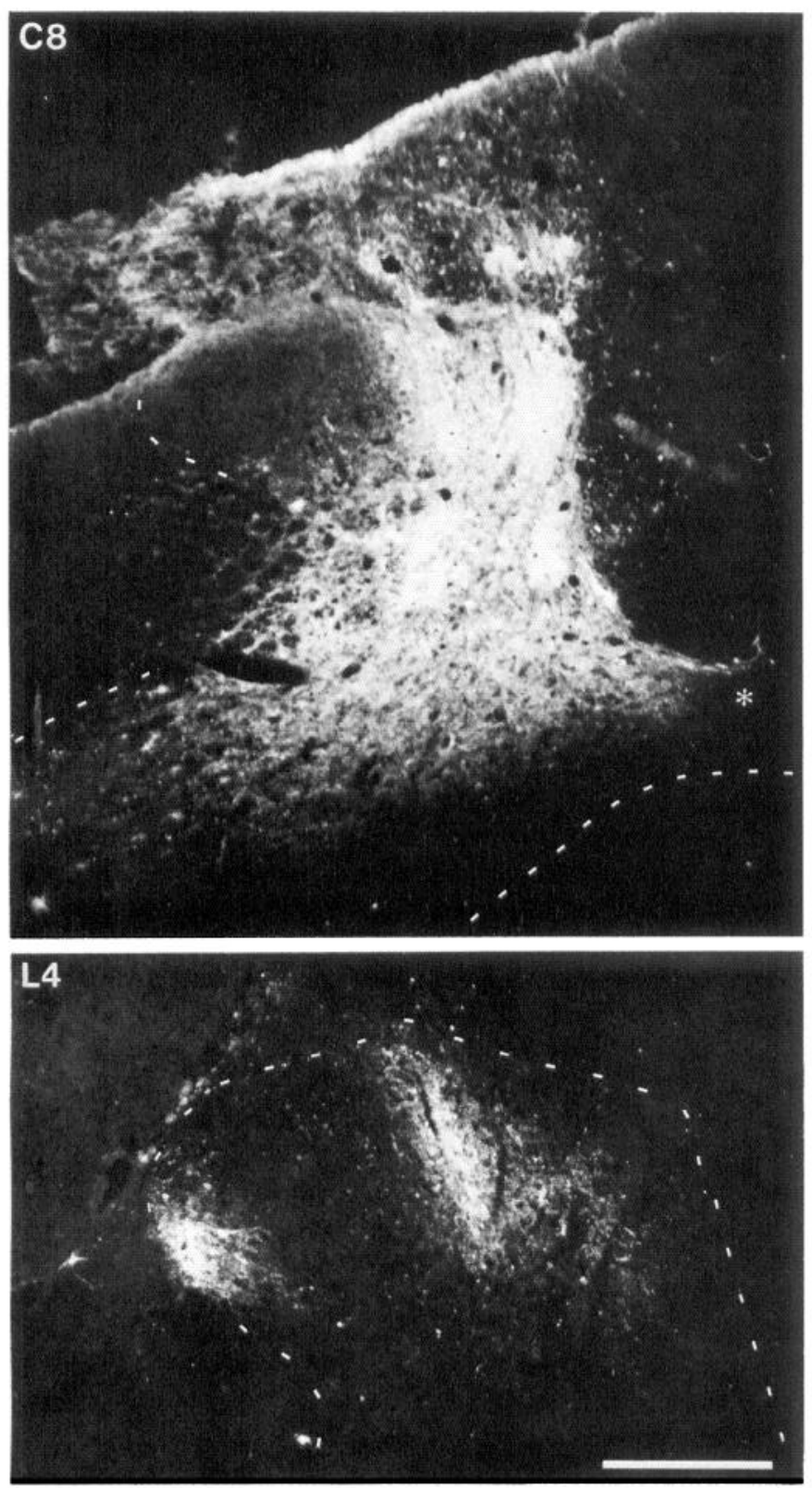

Figure 2. Photomicrographs of examples of injection sites of PHA-L. $T o p$, Injection into segment $\mathrm{C} 8$, consisting of 8 individual injections in 4 tracks in 2 rostrocaudal planes. Dashed lines indicate edge of gray matter. Asterisk, Central canal. Bottom, Injection into segment L4, consisting of 3 injections in a single plane. Scale bar, $0.5 \mathrm{~mm}$ (top); 0.25 $\mathrm{mm}$ (bottom).

stantially involved $(A)$. Ventrally in the diencephalon, zona incerta was partially involved $(B)$, but the hypothalamus was not. Little, if any, Fluoro-Gold spread into the medial thalamus $(B)$.

The distribution of cells retrogradely labeled with FluoroGold in the DCn and cervical spinal cord resembled those reported in previous studies after injections of HRP into the thalamus of rats (Tan and Lieberman, 1978; Giesler et al., 1979a; Feldman and Kruger, 1980). Labeled cells were distributed contralateral to the injection throughout the DCn. In addition, cells were labeled in the external cuneate nucleus, primarily in the caudal portion. The density of labeled cells was especially high at the level of the obex ${ }^{1}$ and for about a millimeter rostrally and caudally (see reconstructions in Figs. 3, 4). The population of labeled cells extended into the cervical spinal cord, with labeled cells in the dorsal columns and the most medial part of the dorsal horn. Labeled cells in these locations were common in $\mathrm{C} 1$, especially rostrally, and relatively sparse through $\mathrm{C} 2$. Caudal to $\mathrm{C} 2$, few labeled cells were seen in the dorsal columns or in the most medial part of the dorsal horn. In other studies, substantial numbers of cells in the medial part of the dorsal horn in C2-4 have been found to project to the thalamus (Giesler et al., 1979a; Granum, 1986; Kemplay and Webster, 1986); the small number of labeled neurons in this study may be the result of our injections not reaching the most rostral VBC. The most rostral part of the $\mathrm{VBC}$ is the part that receives the densest projection from spinothalamic tract neurons caudal to $\mathrm{C} 2$ (Lund and Webster, 1967b). Retrogradely labeled cells were also seen in the contralateral lateral cervical nucleus, in the contralateral spinal trigeminal nucleus, and in the ipsilateral nucleus of the solitary tract.

\section{PHA-L injections}

Examples of multiple injections of PHA-L into the spinal cord are illustrated in Figure 2. The injection illustrated at the top consisted of a total of 8 individual injections in 4 tracks in 2 transverse planes in segment $\mathrm{C} 8$ (the case shown in Fig. 7). As a result, nearly the entire dorsal horn was heavily labeled, including nucleus proprius, the region in which almost all PSDC neurons are found (Giesler et al., 1984). The injection illustrated at the bottom consisted of 3 individual injections within a single plane in segment L4. Labeled neuronal cell bodies could be seen within injection sites. After long survival periods, the diffuse labeling at injection sites in the gray matter of lumbar cord was often relatively light compared with injection sites in the gray matter of cervical cord after shorter survival periods. In contrast, labeling at injection sites remained relatively intense in white matter, even over long survival periods.

Cases with injections of PHA-L into the spinal cord that resulted in substantial numbers of labeled fibers in the DCn included the following: 14 cases with 2-30 injections in the cervical enlargement (C6-T1), survival times 13-40 d; 4 cases with 3-35 injections in mid-thoracic cord (T8-10), survival times 26-36 d; 17 cases with 1-27 injections in the lumbar enlargement (L3-5), survival times 23-39 d; 3 cases with 2-30 injections in sacral cord, survival times 39-41 d.

\section{Absence of retrograde labeling with $P H A-L$}

In 13 animals that received injections into the gray matter of the dorsal horn ( 8 cervical and 5 lumbar injections), we processed and examined DRGs with attached portions of the dorsal roots from the segments of the injections and from adjacent segments. In a few cases, a few labeled fibers were observed in the proximal dorsal roots after injections that impinged on the dorsal root entry zone. We did not observe labeled fibers close to or in the ganglia. Labeled neurons were not seen in any DRG. Within the brain and spinal cord, neurons labeled with PHA-L were almost always confined to the immediate vicinity of the injection site. Labeled neurons were not encountered further than the dorsal horn contralateral to the injection at the same level (one instance).

'Following Papez $(1929 ;$ pp. 121, 196), we use the term "obex" to mean the most rostral level where the 2 gracile nuclei abut one another. 


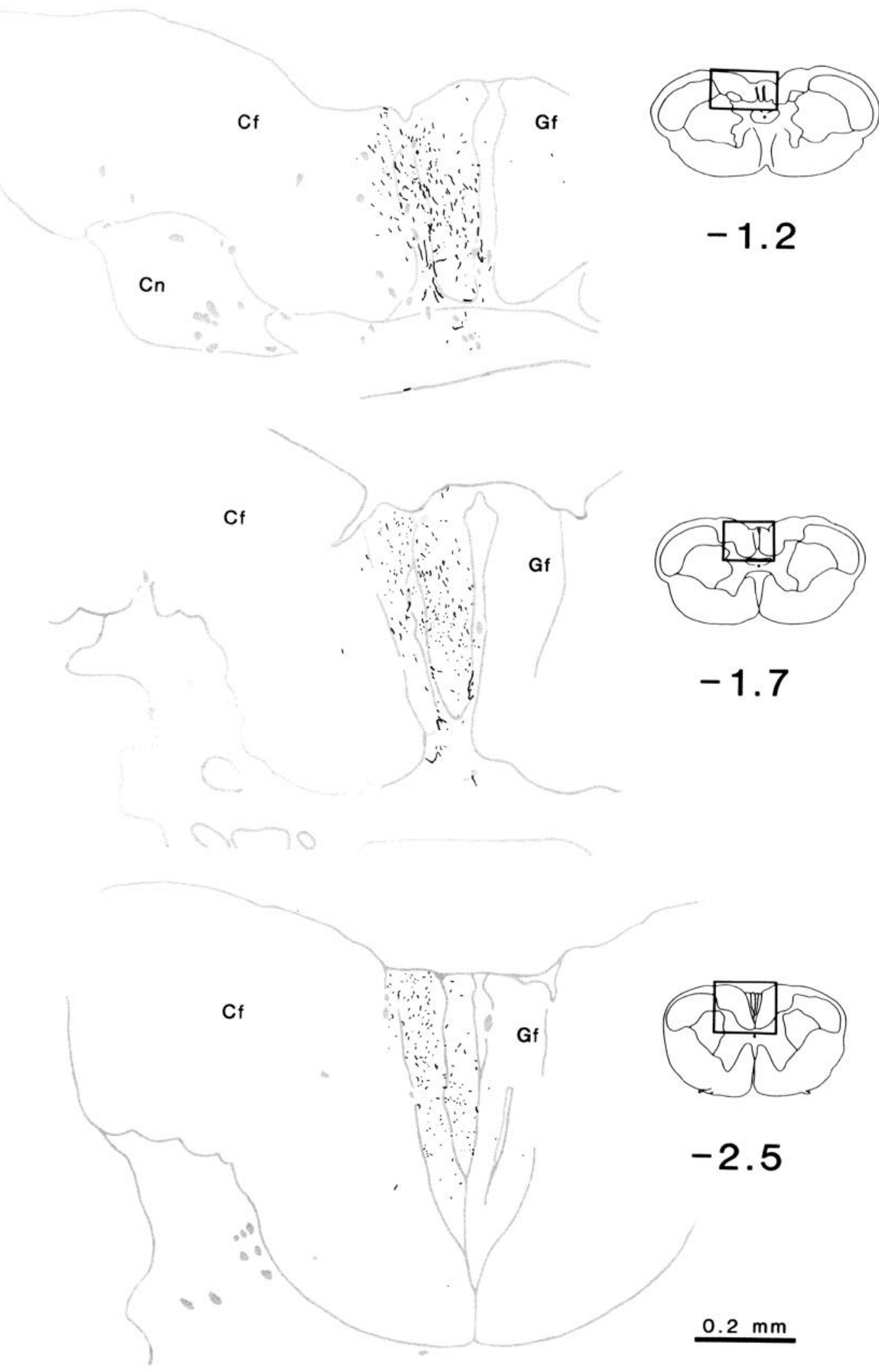

Figure 3. Drawings of labeled fibers in transverse sections through the dorsal column nuclei after 4 injections of PHA-L in a single plane of segment L4. Inset drawings indicate locations of illustrated areas. Cells retrogradely labeled with Fluoro-Gold from injections in the thalamus are depicted in gray. Levels indicated by approximate distance in millimeters from obex (calculated by numbers and thicknesses of sections); positive is rostral. Borders drawn from architectonic structure seen with dark-field illumination. $A P$, Area postrema; $C f$, cuneate fasciculus; $C n$, cuneate nucleus; $E C n$, external cuneate nucleus; $G f$, gracile fasciculus; $G n$, gracile nucleus. Scale bars, $0.2 \mathrm{~mm}$. (See following 2 pages for continuation of this figure.) 


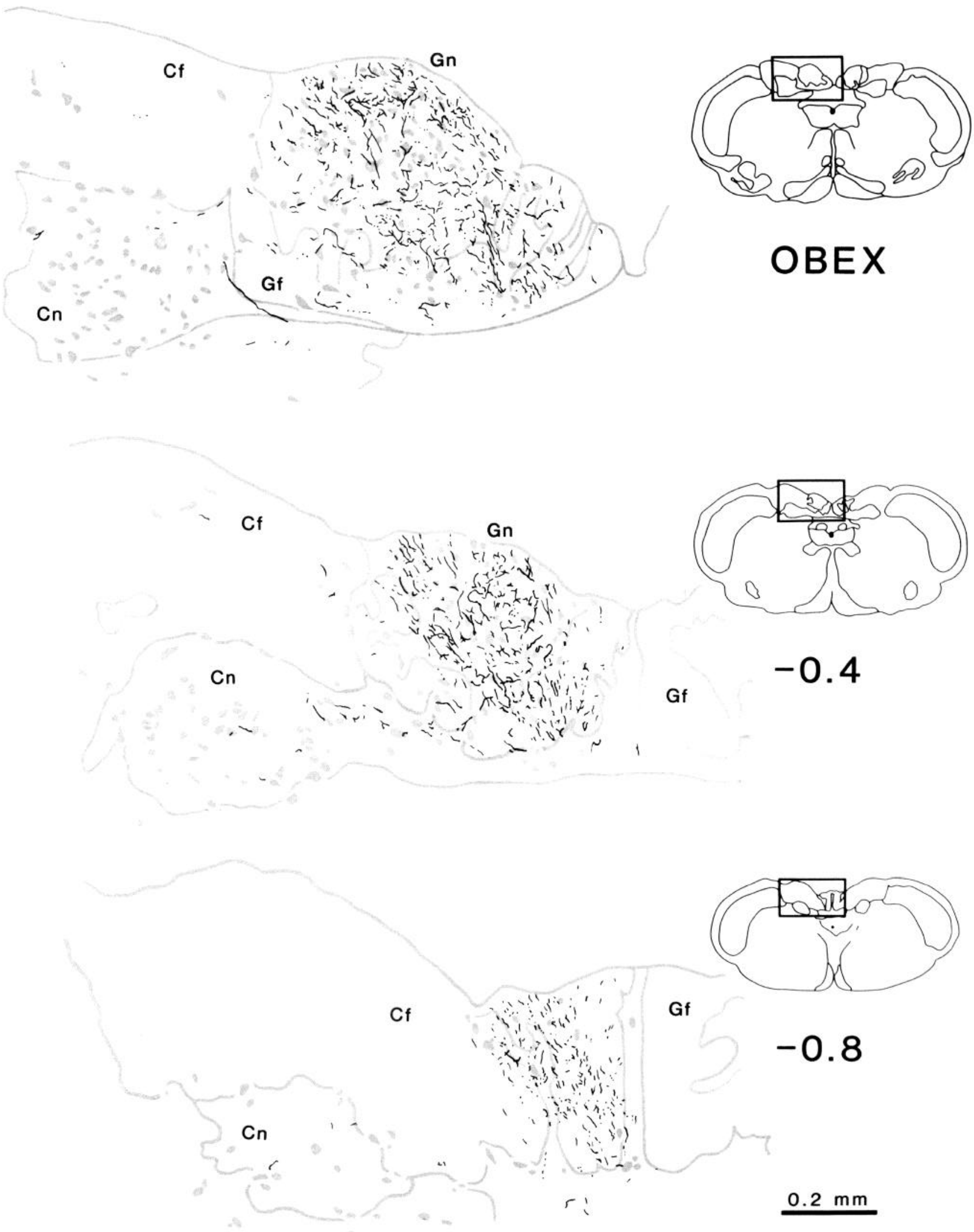



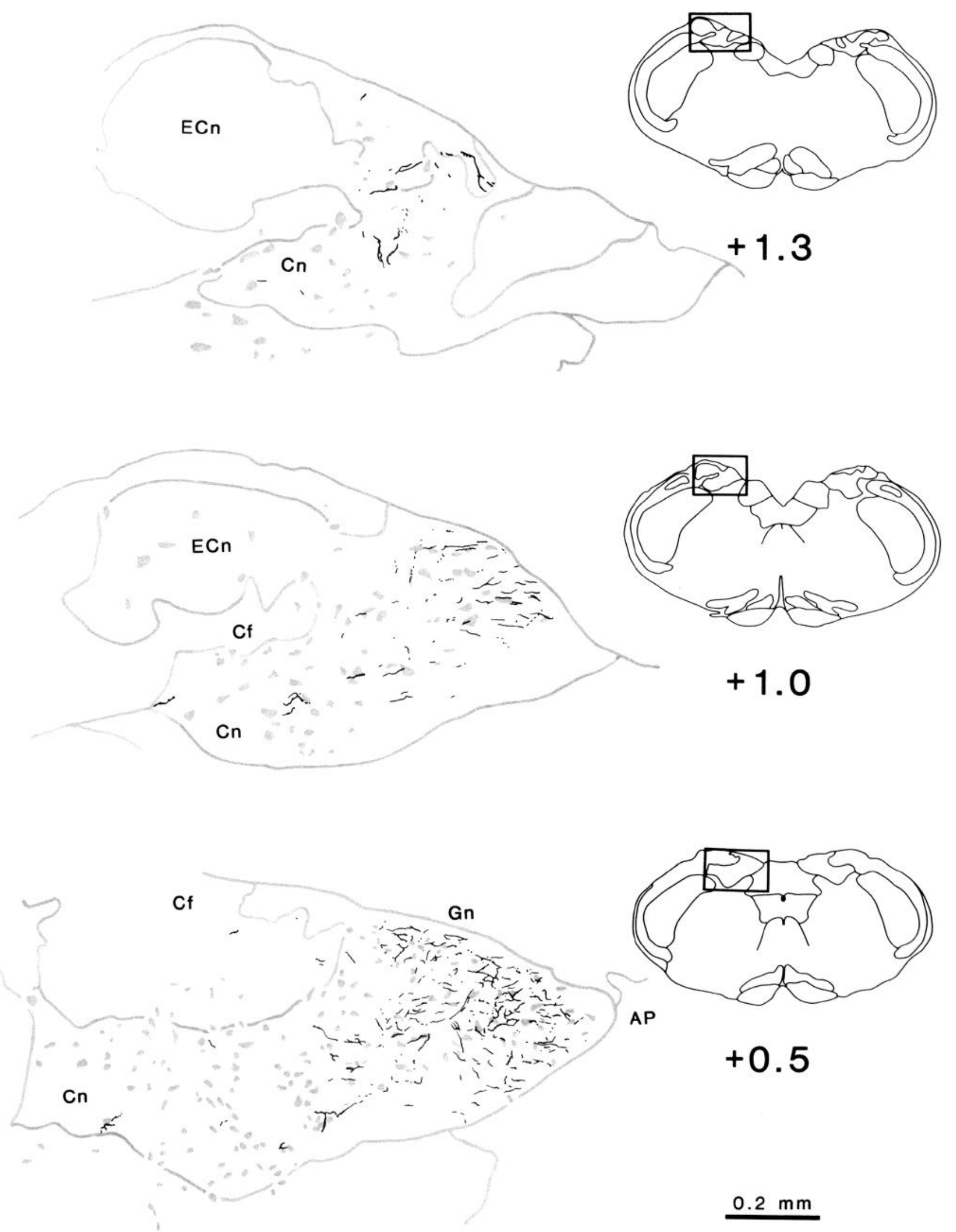

Figure 3. Continued. 


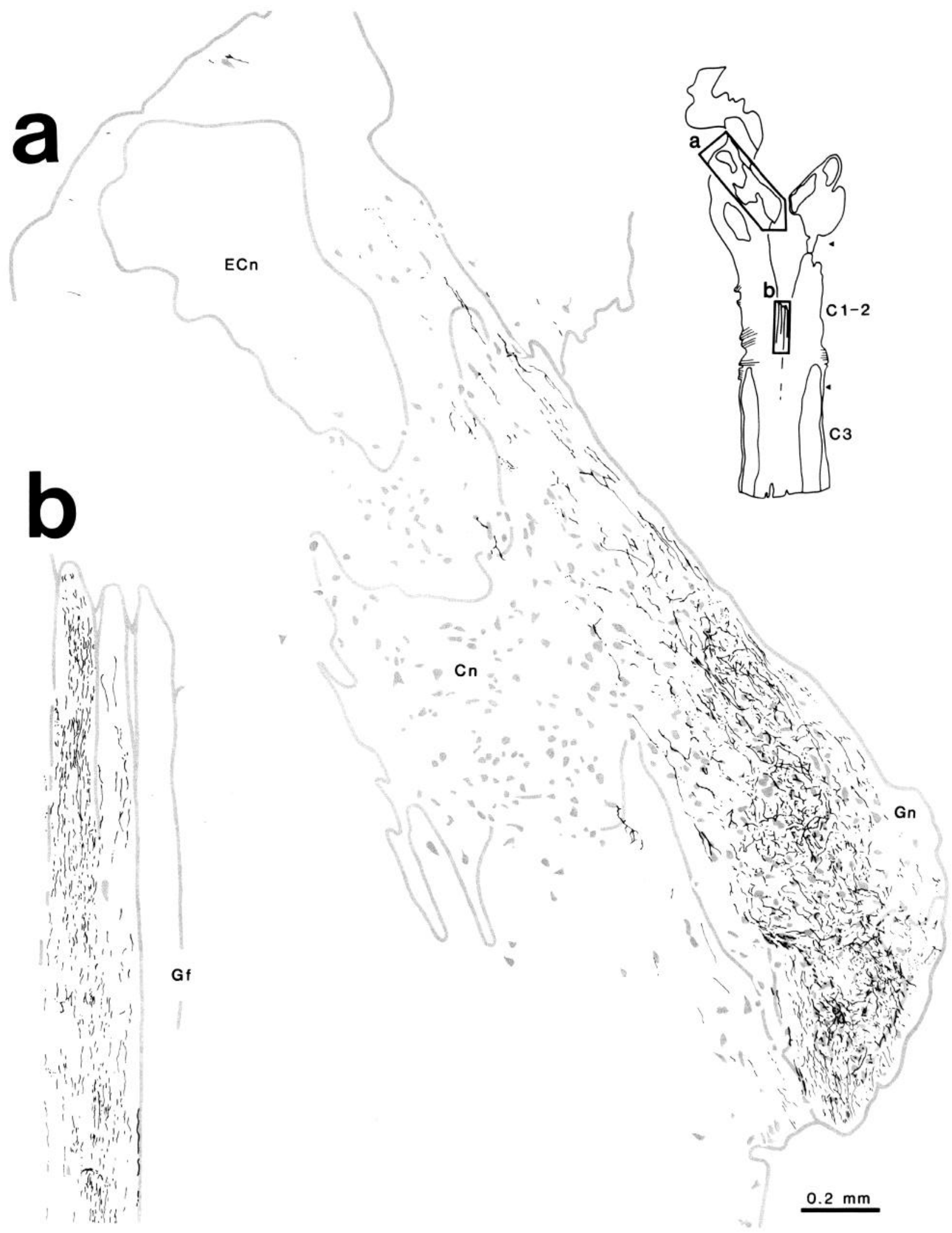

Figure 4. Drawings of labeled fibers in horizontal sections through the dorsal column nuclei after 6 injections of PHA-L in a single plane of segment L4. Inset drawings indicate locations of illustrated areas progressing from dorsal to ventral (A-F) in sections separated by approximately $100 \mu \mathrm{m}$. Cells retrogradely labeled with Fluoro-Gold from injections in the thalamus are depicted in gray. Borders drawn from architectonic structure seen with dark-field illumination. Abbreviations as in Figure 3. Scale bars, $0.2 \mathrm{~mm}$. This page: Figure 4A. 


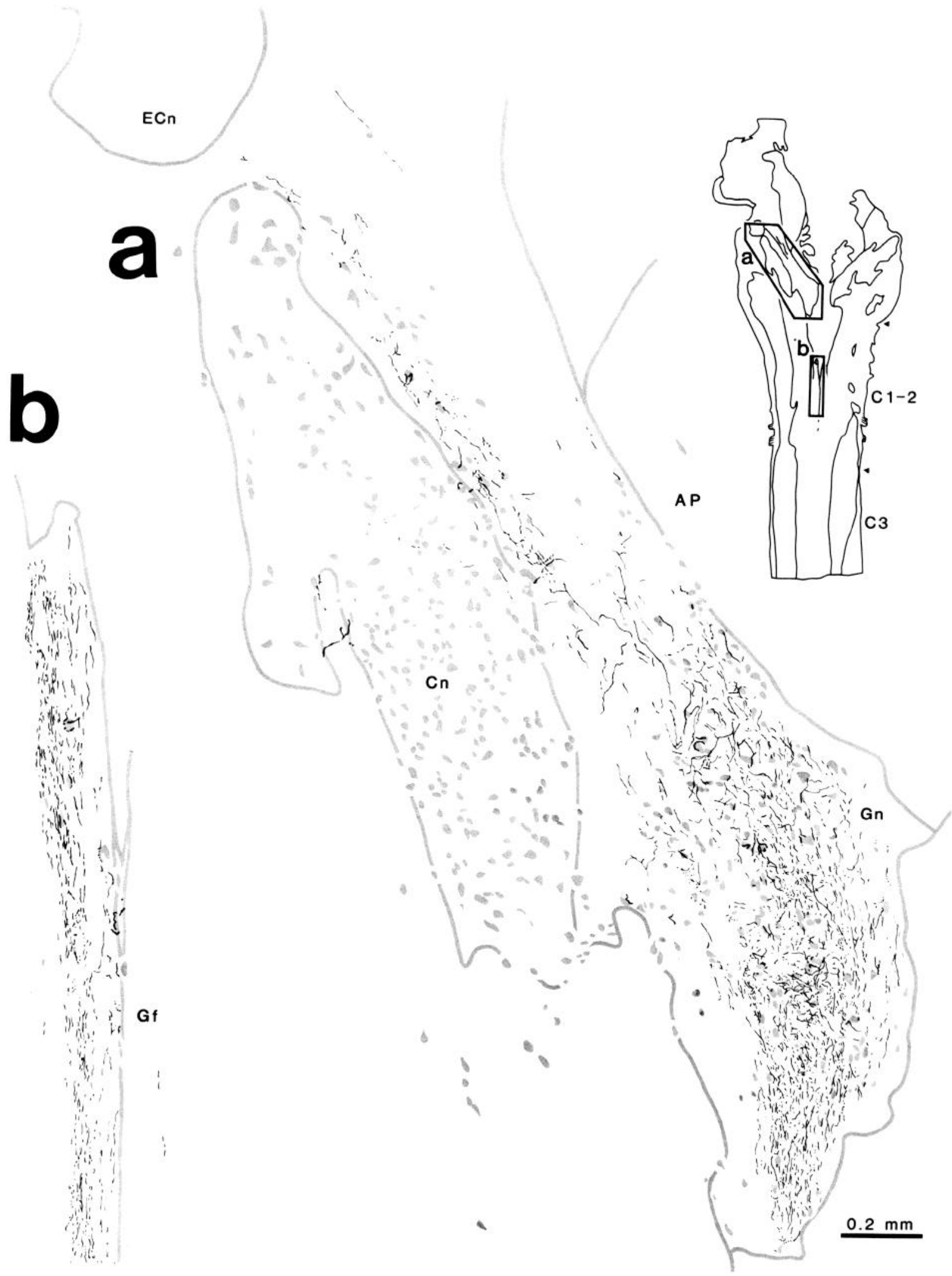

Figure 4B. 


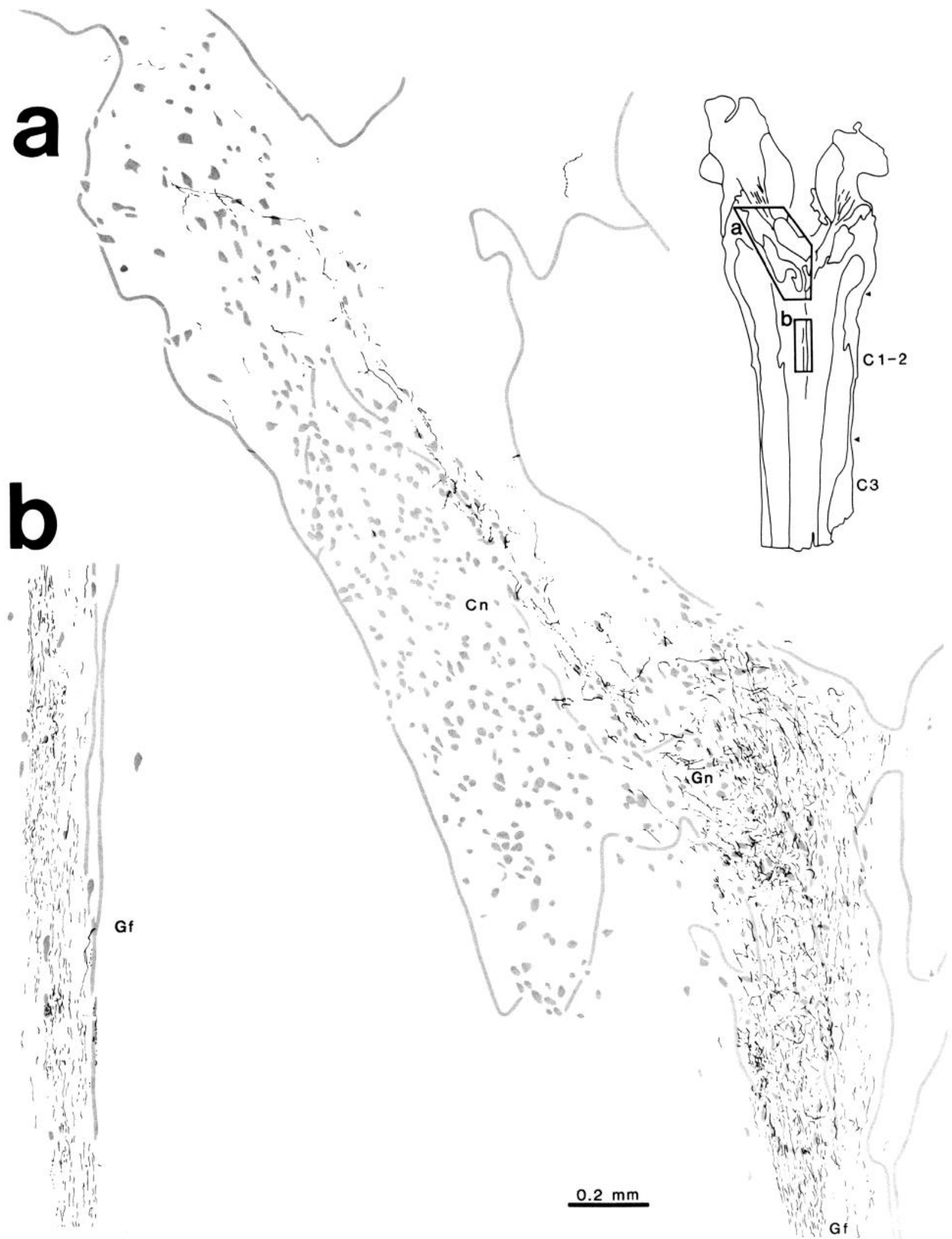




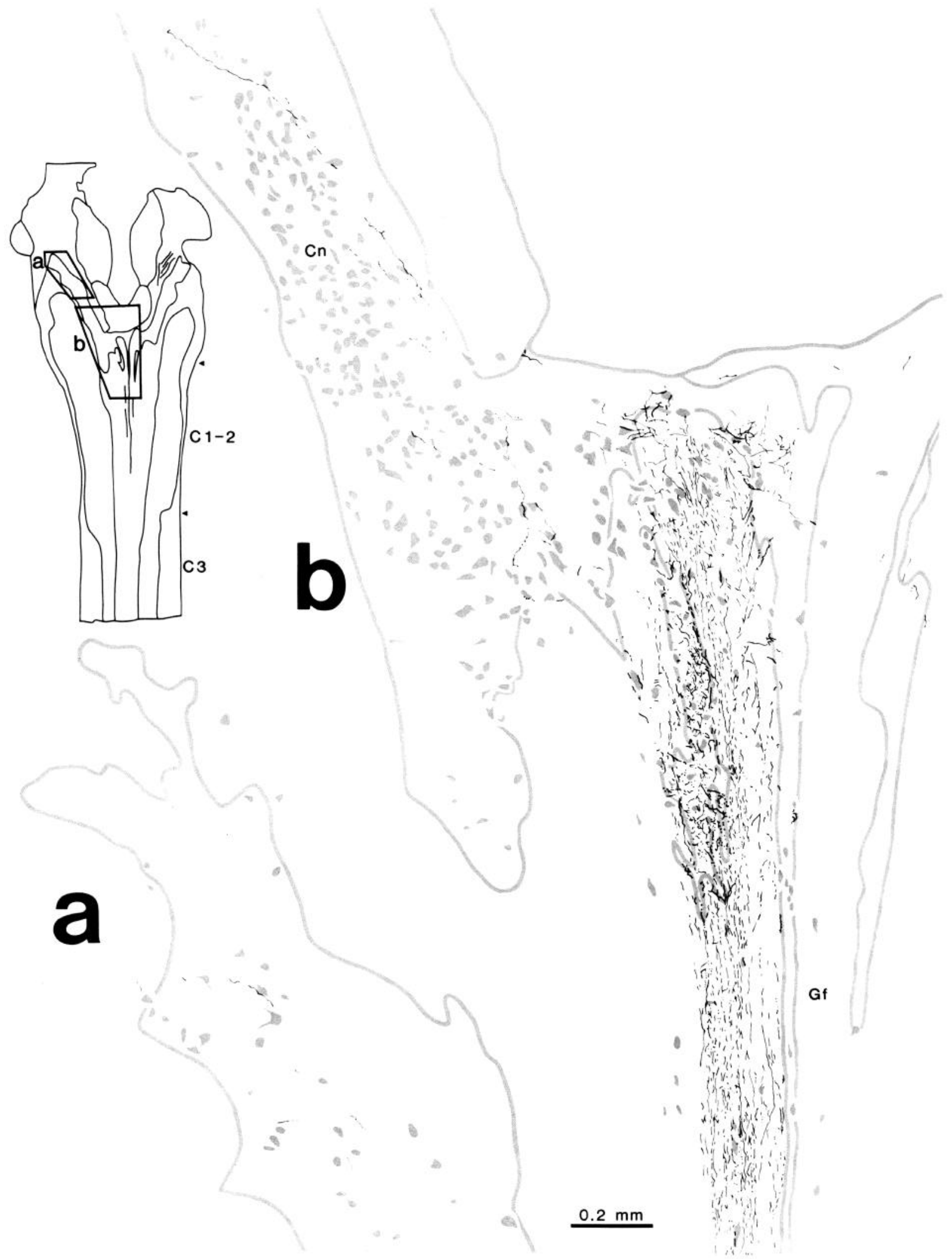




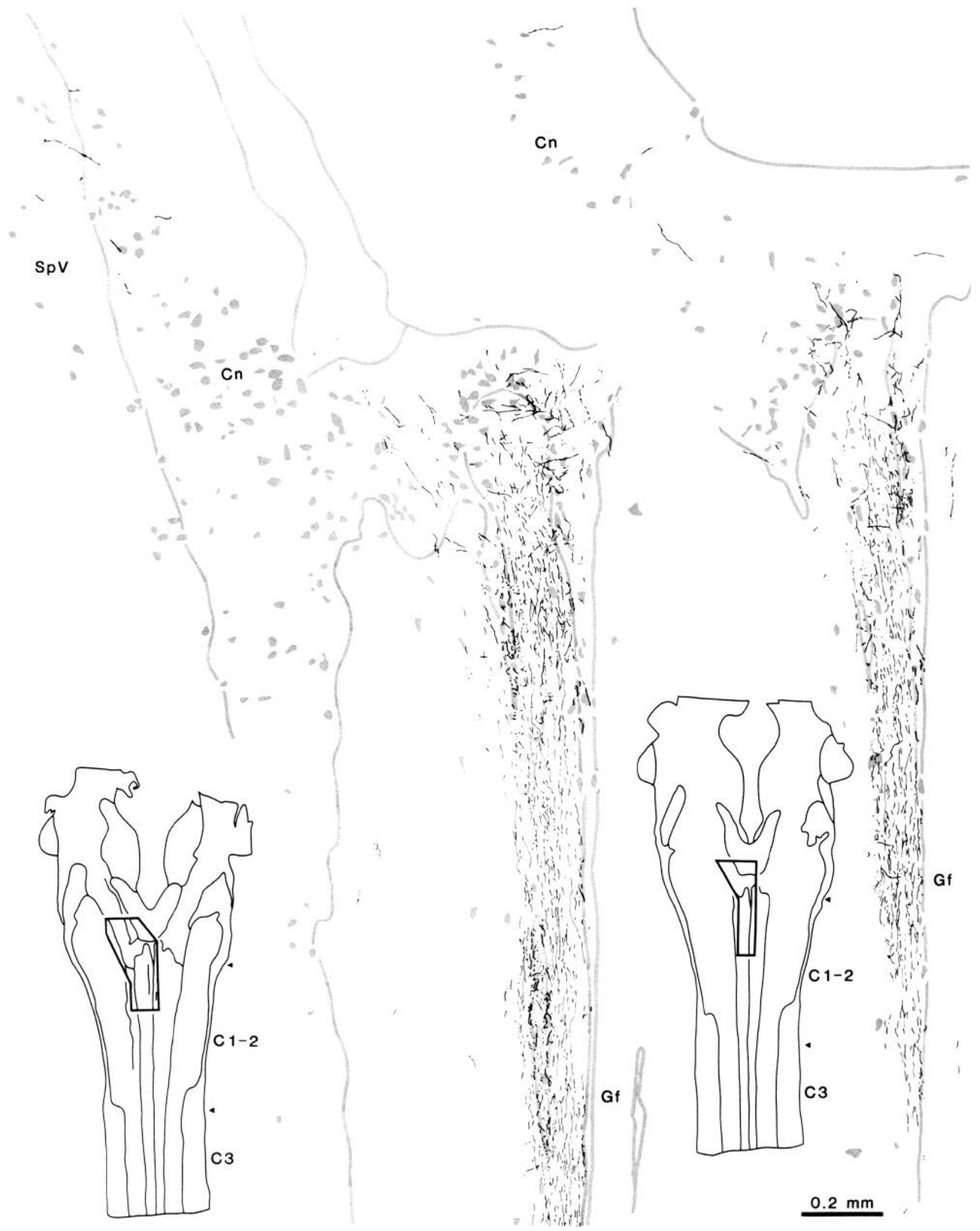

Figure 4. E (left) and F (right). 


\section{LEVEL OF INJECTION}
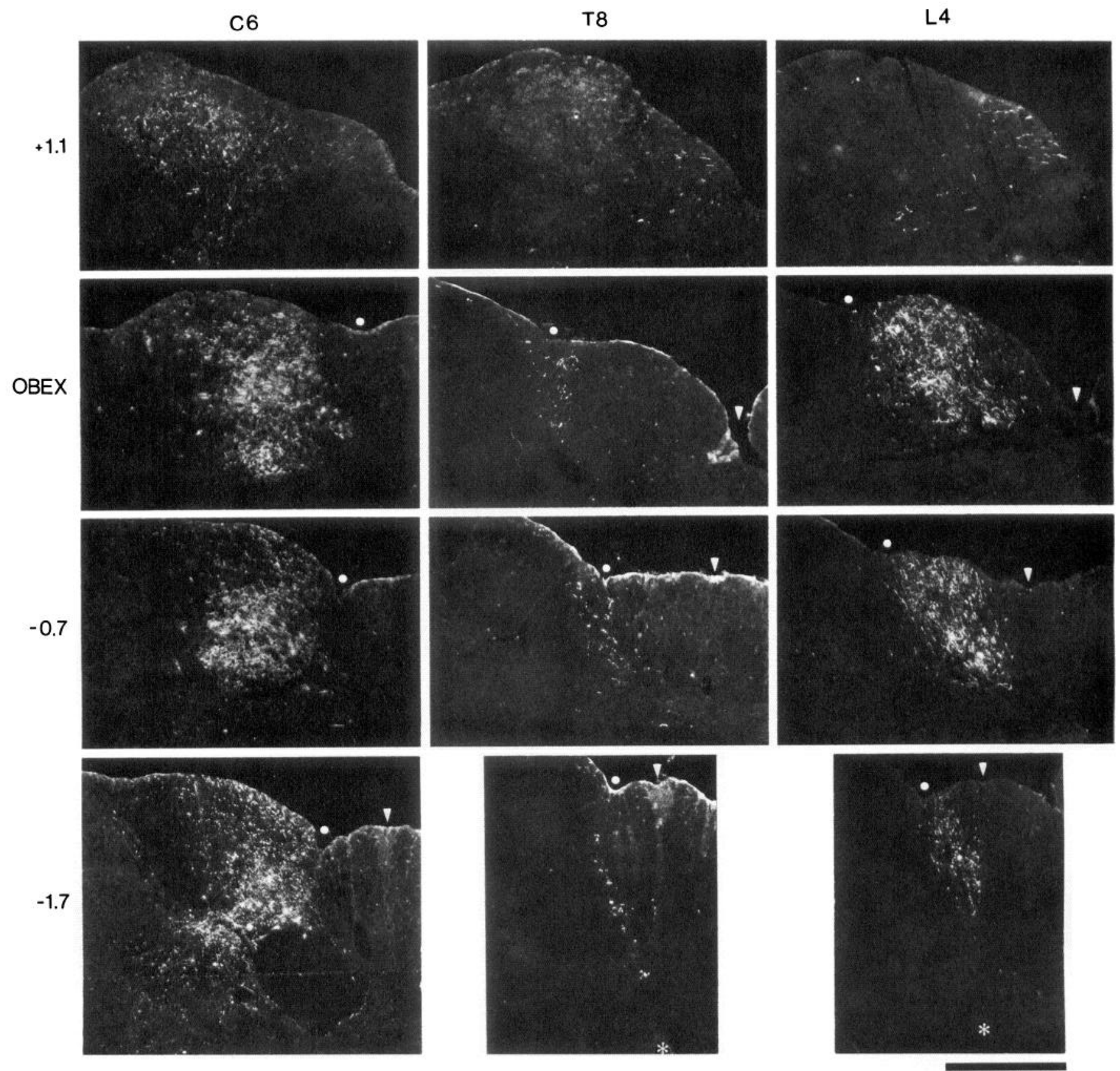

Figure 5. Photomicrographs of transverse sections showing immunohistochemical staining for PHA-L in the DCn. Levels of injections are indicated at the top. Approximate distance from the obex is indicated at the left in millimeters (calculated by numbers and thicknesses of sections); positive is rostral. Dot, Dorsal intermediate sulcus, between gracile and cuneate complexes; arrowhead, midline; asterisk, central canal. Scale bar, $400 \mu \mathrm{m}$.

\section{Distribution of labeled fibers}

Lumbar injections. Nearly all of the ipsilateral gracile nucleus contained labeled fibers after unilateral injections made in single transverse planes in the lumbar enlargement. Figures 3 and 4 are reconstructions of the locations of all labeled fibers in selected transverse and horizontal sections of the dorsal column fasciculi and nuclei after injections of PHA-L in segment L4 of the spinal cord (4 and 6 injections for the cases illustrated in Figs. 3 and 4, respectively). Architectonic boundaries and neu- rons retrogradely labeled with Fluoro-Gold are shown in gray. The wide distribution of labeled fibers in the ipsilateral gracile nucleus after injections in the lumbar enlargement can be seen also in Figure 5. Labeled varicosities were observed throughout all nuclear regions of the gracile complex. Injections into the lumbar cord also resulted in occasional labeled fibers contralateral to the injection and in the ipsilateral cuneate fasciculus and nucleus (Figs. 3-5).

Thoracic injections. After injections of PHA-L into thoracic spinal cord, labeled fibers were observed primarily in the lateral part of the gracile nucleus and the medial part of the cuneate 
3158 Cliffer and Giesler

Figure 6. Photomicrographs of horizontal sections through the dorsal column nuclei, showing labeling from an injection of PHA-L in segment T10. Note that labeled fibers are at or near the border between the gracile and cuneate nuclei. Note also fibers extending rostrally from the area of densest labeled fibers. $A$ is more dorsal; $C$, cuneate nucleus; $C f$, cuneate fasciculus; $G$, gracile nucleus. Scale bar, $500 \mu \mathrm{m}$.

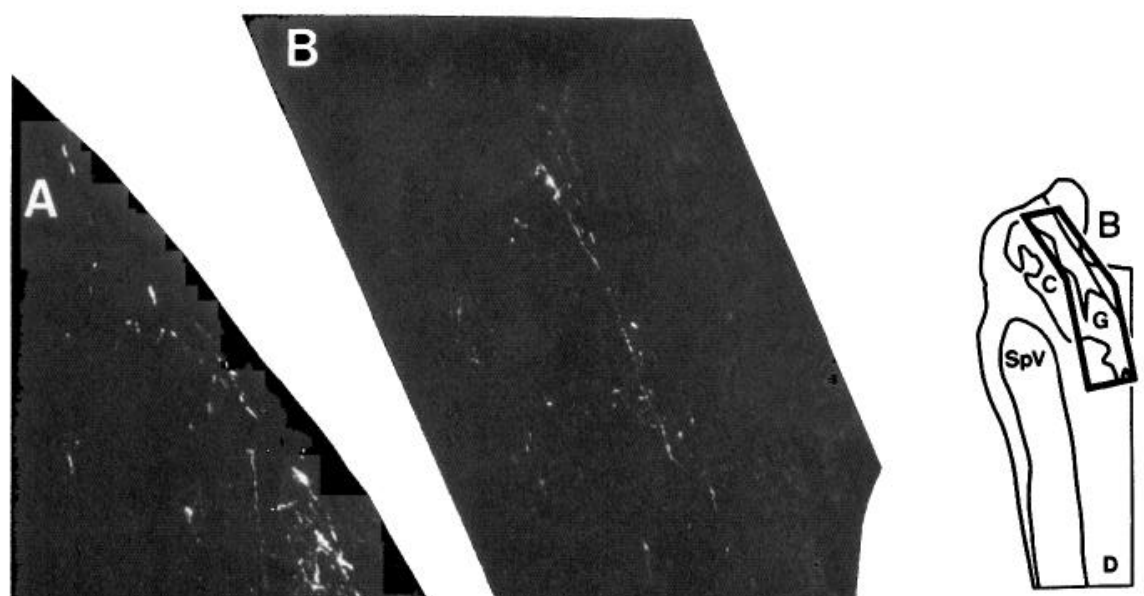

C

C

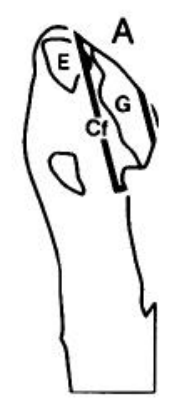



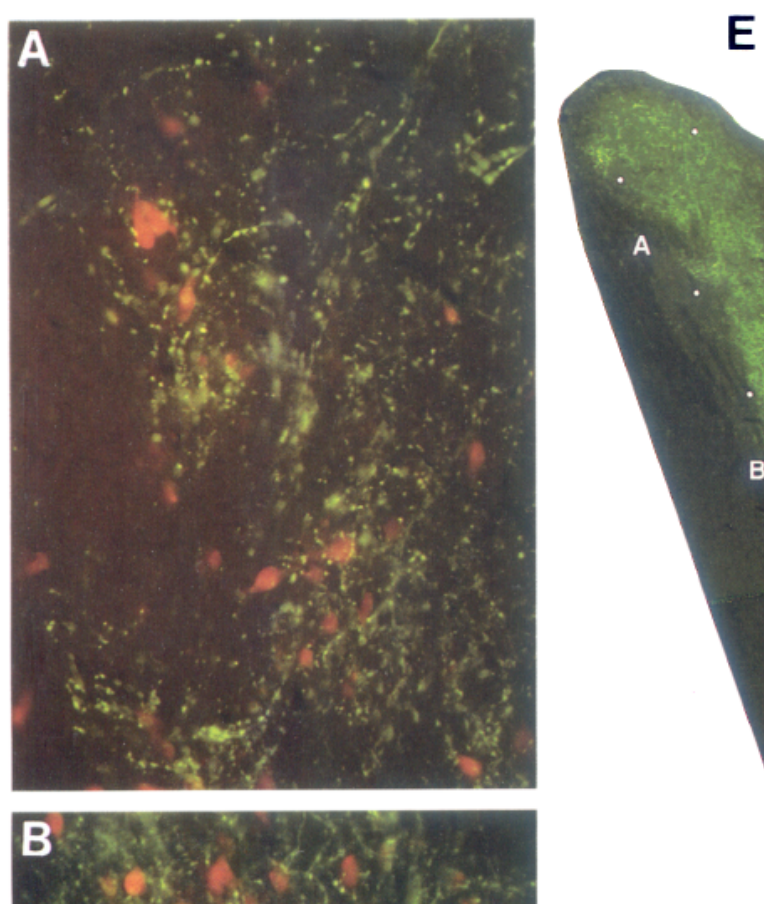

E

$\mathbf{F}$

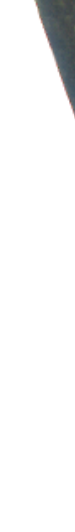

A
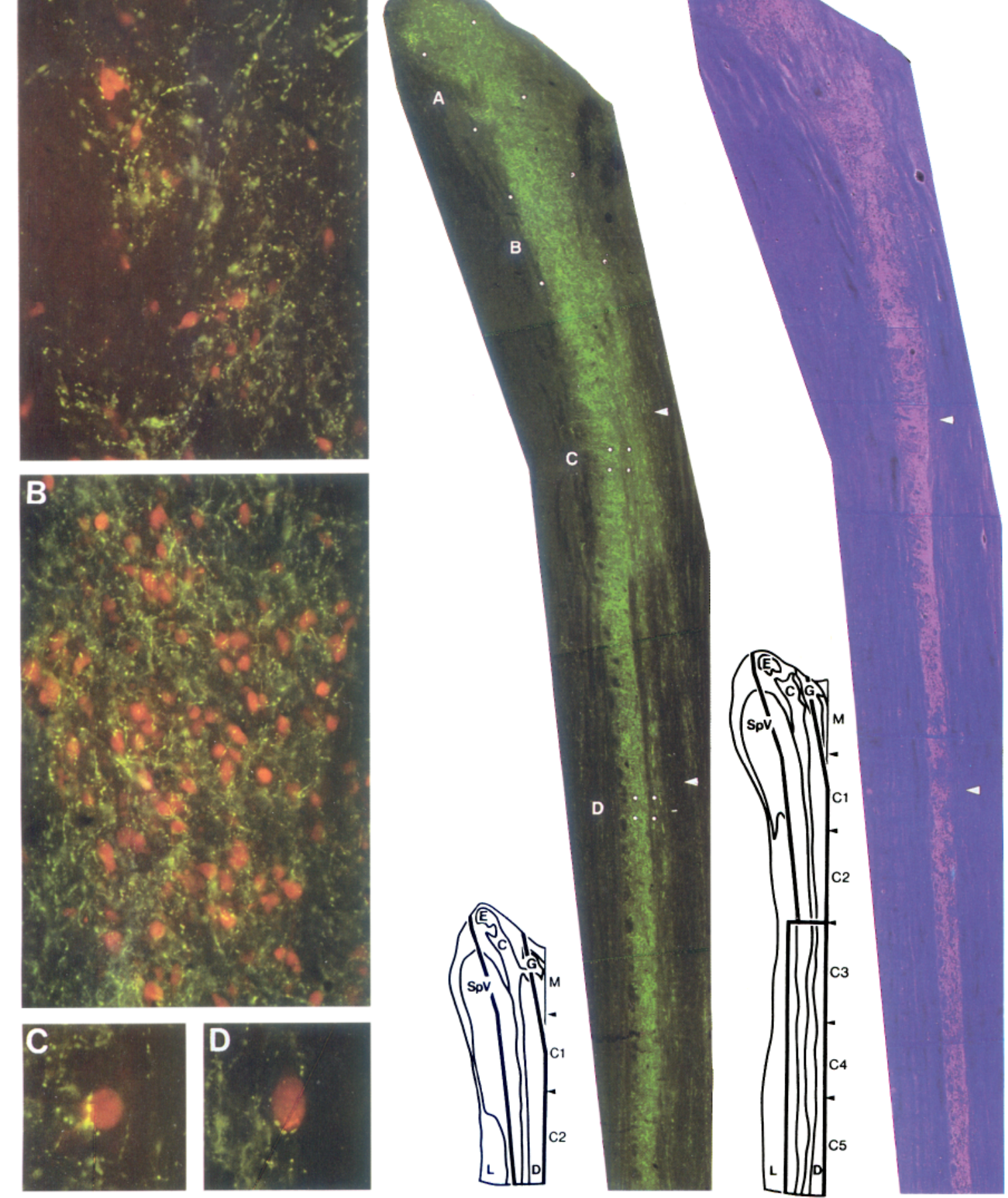

G

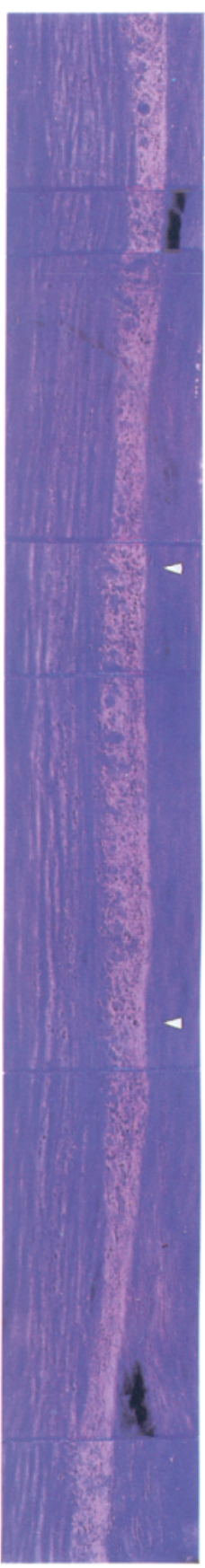

Figure 7. Photomicrographs of labeling in horizontal sections following 5 injections of PHA-L in a single plane in segment C6 (A-E; same case as in Fig. 8, $C, D)$ or following injection of B-HRP into the DRG of segment $C 7(F, G$; same case as in Fig. $8 F)$. $A-D$, Double-exposed photomicrographs of labeling in locations indicated by dots in $E$, showing anterogradely labeled fibers and varicosities (green/yellow) apposed to retrogradely labeled cells (red). E, Photomicrograph of single horizontal section showing extent of anterograde labeling from external cuneate nucleus through C2. Location shown in drawing to left of photomicrograph. $F$, Photomicrograph of similar view to $E$ of anterograde labeling by B-HRP. This is a composite photomicrograph taken from several sections since the angle of sectioning was not proper to get the entire extent in one section. $G$, Similarly composite photomicrograph, caudal to area shown in $F$. Locations of $F$ and $G$ are indicated in drawing to left of $F$. In $E-G$, divisions between segments are indicated by arrowheads, corresponding to those in the drawings. Abbreviations in drawings: $C$, cuneate nucleus; $D$, dorsal columns; $E$, external cuneate nucleus; $G$, gracile nucleus; $L$, lateral funiculus; $M$, medulla; $S p V$, spinal trigeminal nucleus. Scale bars, $A, B$, 100 $\mu \mathrm{m} ; C, D, 50 \mu \mathrm{m}$ (lower left); $E-G, 1 \mathrm{~mm}$ (lower right). 

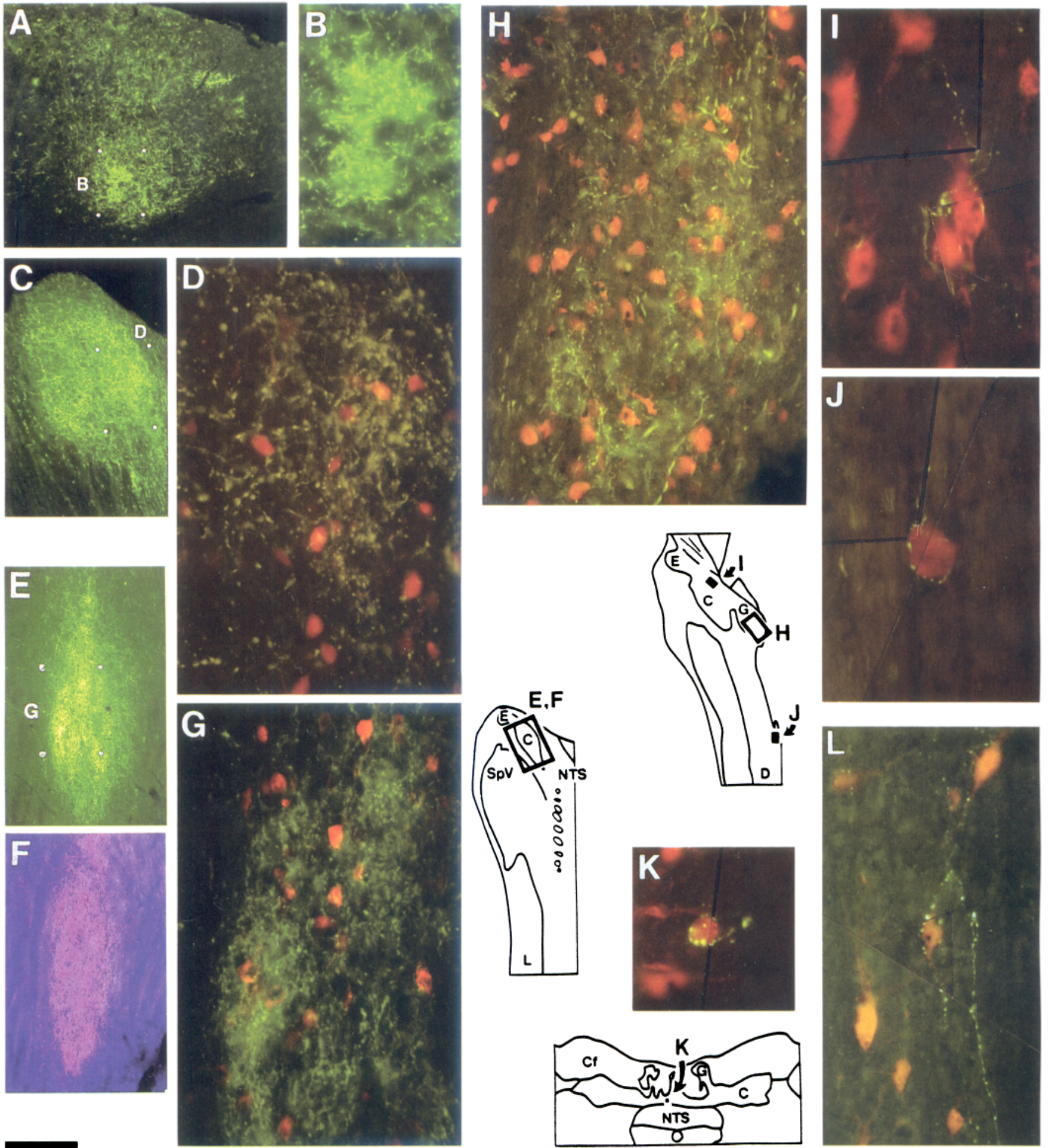

Figure 8.

\section{Phot}

rograph of labeling in a transverse section

ough the cuneate nucleus approximately $0.5 \mathrm{~mm}$ rostral to obex, following 6 area in area indicated in $A$. C , Photomicrograph of labeling in a horizontal section through the external cuneate nucleus following 5 injections of PHA-L ig. $7, A-E$ ). Location of $D$ is indicated by dots in corners. $D$, Higher power, double-exposed photomicrograph of area indicated in $C$, showing retrogradely labeled cells (red) in an area of dense anterogradely labeled fibers. $E$, Photomicrograph of labeling in a horizontal section through the ventral part of the cuneate nucleus following 8 injections of PHA-L in 2 transverse planes about $400 \mu \mathrm{m}$ apart in segment C6. Location of $\mathrm{G}$ is indicated by dots in corners. $F$, Photomicrograph of similar section to that in $\mathrm{E}$ following injection of B-HRP into DRG of segment $C 7$ (same case as in Fig. 7, $F, G$ ). Locations of $E$ and $F$ indicated in drawing. $G$, Higher power, double-exposed photomicrograph of area indicated in $E$ showing retrogradely labeled cells (red) in an area of dense anterogradely labeled fibers. $H-J$, Doubleexposed photomicrographs of labeling in horizontal sections through the dorsal column nuclei in same case depicted in Figure 4. Locations of photomicrographs indicated in drawing. $K$, Double-exposed photomicrograph of labeling in transverse section of ventral, caudal part of gracile nucleus (level about $0.4 \mathrm{~mm}$ caudal to obex) showing labeled varicosities apposed to retrogradely labeled cell. Location indicated in drawing. $L$, Double-exposed photomicrograph of labeling in horizontal section through the LCn (same case as in E) showing anterogradely labeled fibers and 
nucleus, on the ipsilateral side (transverse sections, Fig. 5; horizontal sections, Fig. 6).

Cervical injections. Injections of PHA-L into the cervical enlargement labeled a large number of fibers throughout most of the ipsilateral cuneate nucleus. Labeled fibers were also seen in the external cuneate nucleus and the internal basilar nucleus (IBn; Ramón y Cajal, 1909; Torvik, 1956). The extent of labeled fibers after injections into the cervical enlargement is illustrated in photomicrographs of transverse sections (Fig. 5) and of a single horizontal section (Fig. $7 E$ ); in both cases the injections were in C6. In these cases labeling was observed from caudal $\mathrm{C} 2$ through the rostral poles of the cuneate and external cuneate nuclei. Horizontal sections from 2 additional cases in which PHA-L was injected into the cervical enlargement (C8) were taken caudally through $\mathrm{C} 6$; we observed labeled fibers extending within the IBn as far as the caudal border of C6. Large varicosities (approximately 3-5 $\mu \mathrm{m}$ diameter) were labeled in the external cuneate nucleus; few large varicosities were seen in the remainder of the DCn (Fig. 7, compare $A, B$ ). A few labeled fibers were found in the ipsilateral gracile nucleus and in the contralateral cuneate nucleus.

Although labeling was present throughout the cuneate nucleus, the density of labeled fibers often varied from one location to another. Figure $8 A$ illustrates a section showing variability in density of the PHA-L-labeled fibers, with a view at higher magnification $(B)$ of an area containing an especially high density of labeled fibers.

After cervical injections, labeled fibers were distributed widely in the cuneate fasciculus (Fig. 9). A few were observed within the area occupied by the pyramidal tract in the ventral part of the dorsal columns (Fig. 9). Fibers in this position were not as common more rostrally (Fig. 5, level -1.7 ), suggesting either that they were propriospinal fibers or that they shifted to positions outside of this tract. A tail of labeled fibers could be observed at rostral cervical levels, extending from the main body of labeled axons ventromedially toward the medial ventral border of the dorsal columns (Fig. 5, level -1.7; Fig. 9, C2). As these fibers were followed further rostrally, they appcarcd to lead to the ventral part of the gracile nucleus (see below).

Sacral injections. Injections of PHA-L in the sacral cord labeled fibers within the most medial part of the ipsilateral gracile nucleus (Fig. 10). In these cases, labeling was not seen in the gracile nucleus rostral to the area postrema.

\section{Relationship of PSDC fibers and varicosities to retrogradely labeled lemniscal cells}

Injections of PHA-L into the spinal cord labeled many fibers and varicosities in the areas of the DCn in which retrogradely labeled lemniscal cell bodies were located. In cases in which PHA-L was injected into lumbar or cervical cord, the varicosities of labeled fibers were closely apposed to retrogradely labeled neurons in all parts of the gracile nucleus (Figs. $3 ; 4 ; 8$, $H-K$ ) or cuneate nucleus (Fig. 7, $A-D$ ), respectively. Notably, many rctrogradely labeled neurons were present in areas with especially high densities of fibers labeled with PHA-L. Figure $8, D$ and $G$, shows retrogradely labeled lemniscal neurons in such areas, both in the cuneate $(G)$ and external cuneate nuclei $(D)$. The many labeled fibers in Figure $8 B$ also surrounded labeled neurons (not shown).

\section{Relationship of PSDC fibers to primary afferent input}

Injections of B-HRP into DRGs of the cervical enlargement labeled many fibers in a dense and widespread distribution throughout the cuneate nucleus. This laheling extended in the IBn at least as far caudally as the $\mathrm{C} 5 / 6$ border (Fig. $7, F, G$ ). The distribution of labeled primary afferent fibers corresponded closely to the distribution of PSDC fibers labeled with PHA-L (Fig. 7, $E, F$ ). Both B-HRP and PHA-L also labeled many fibers throughout the most ventral part of the cuneate nucleus (Fig. 8, $E, F)$. These results show that the distributions of postsynaptic afferent fibers and of primary afferent fibers to the cuneate nucleus occur in equivalent areas, with some areas having dense concentrations of both types of fibers.

To examine directly the distributions of primary and postsynaptic afferent fibers in the same animal, adjacent sections were processed for PHA-L or B-HRP. The results from one such case are illustrated in Figure 11. Although not all areas had equivalent densities of afferent fibers from the 2 sources, the overlap was extensive throughout the nucleus, and in many areas both types of fibers were particularly dense.

Primary afferent fibers and postsynaptic fibers overlapped not only within the DCn, but also as they ascended in the dorsal columns. Widespread distributions of labeled fibers observed after cervical injections of PHA-L are illustrated in Figures 5 (level -1.7 , left) and 9. Overlap of the distributions is directly indicated in adjacent sections in Figure 11, especially at level -1.4 .

Dense labeling of primary afferent fibers in the IBn extended continuously from the segment of the injection to the cuneate nucleus (Fig. 7, $F, G$ ). Figure 12 illustrates examples of such labeling in transverse sections at $\mathrm{C} 6$ and $\mathrm{C} 4$ in a case that received injections into the DRGs of segments $\mathrm{C} 7$ and $\mathrm{C} 8$. In $\mathrm{C} 6$ dense labeling of primary afferent fibers was distributed widely within much of the dorsal horn (Fig. 12). However, the substantia gelatinosa and the lateral reticulated area contained almost no labeled fibers. Robertson and Grant (1985) previously reported that injections of B-HRP do not label a large number of fibers in the superficial dorsal horn and lateral reticulated area, a finding they attributed to the selectivity of B-HRP for larger diameter fibers. In $\mathrm{C} 4$, the densest label was restricted to the ventromedial dorsal horn, including the IBn. Comparison with Figures $9(\mathrm{C} 2)$ and $11(\mathrm{C} 2 / 3)$ reveals the similarity of the location of the concentrated labeling in transverse sections to that produced by PHA-L injections. Like Robertson and Grant (1985), we never saw cell bodies labeled by B-HRP in the dorsal horn after injections of DRGs, even among dense accumulations of labeled fibers.

\section{Deeper labeling}

The most ventral part of the gracile nucleus (ventral to the gracile fasciculus; Fig. 3), from the caudal limit of the pyramidal decussation rostrally to the obex, consistently contained a few

varicosities in apposition to retrogradely labeled cells. Note varicosity apposed to dendrite of cell at upper right, as well as many apposed to cell at center. Rostral is up. Abbreviations in drawings: $C f$, cuneate fasciculus; $N T S$, nucleus of solitary tract; other abbreviations as in Figure 7. Scale bar, $240 \mu \mathrm{m}(A) ; 120 \mu \mathrm{m}(\mathrm{B}) ; 340 \mu \mathrm{m}(C, F) ; 320 \mu \mathrm{m}(E) ; 60 \mu \mathrm{m}(D, G, L) ; 70 \mu \mathrm{m}(H) ; 35 \mu \mathrm{m}(I-K)$. 

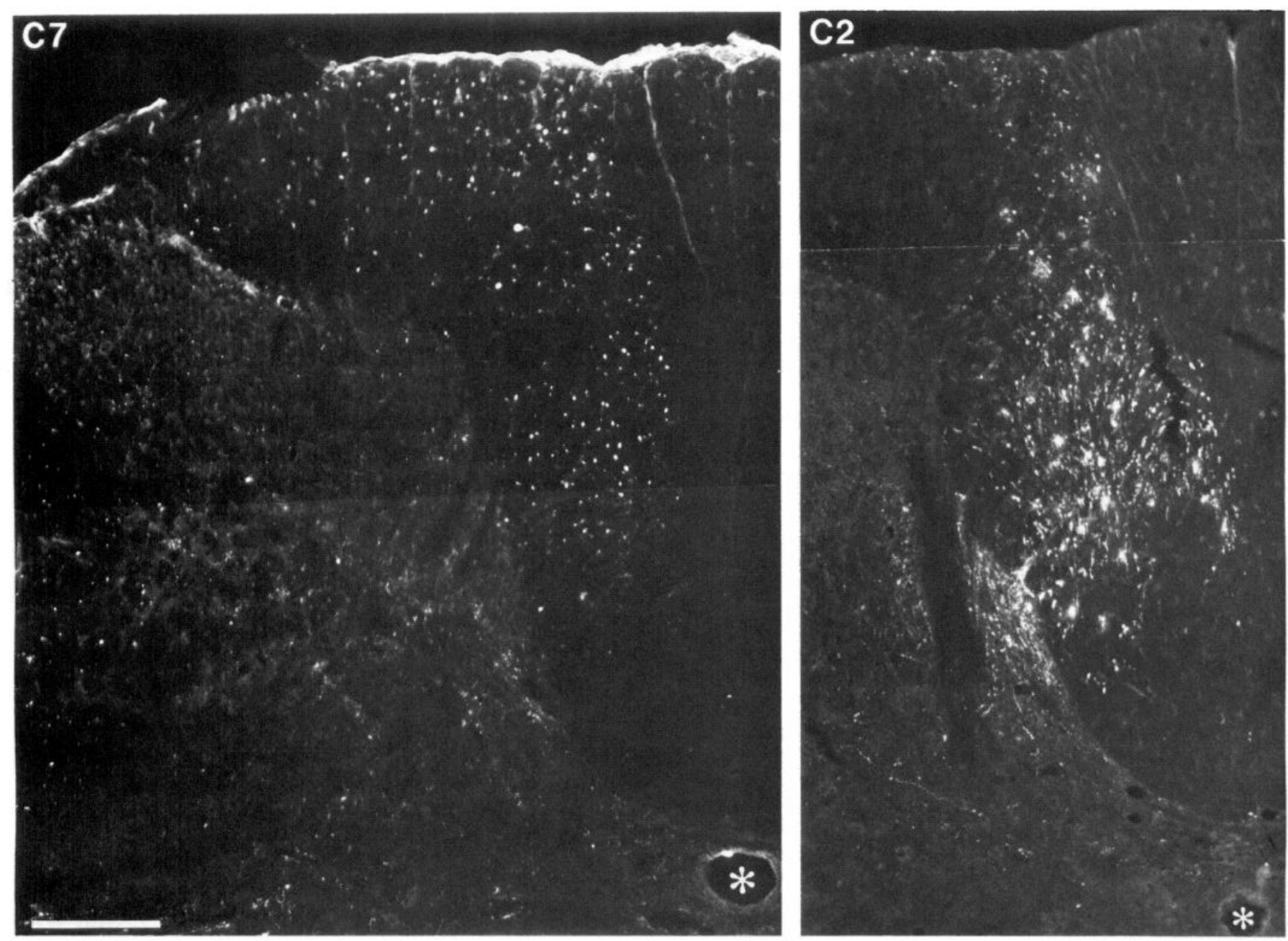

Figure 9. Photomicrographs of transverse sections through levels $\mathrm{C} 7$ and $\mathrm{C} 2$ of the spinal cord following 8 injections of $\mathrm{PHA}-\mathrm{L}$ in 2 transverse planes about $0.6 \mathrm{~mm}$ apart in segment C8 (left) and following a single injection of PHA-L in a single plane in segment C6 (right; same case as in Fig. 5, left). Note locations of ascending labeled fibers. Some burst artifacts are evident in dorsal columns of C2; these are not uncommon. Asterisks, Central canal. Scale bar, $200 \mu \mathrm{m}$.

labeled fibers in cases that received injections at cervical, thoracic, or lumbar levels (Fig. 3 , levels $-0.4,-0.8,-1.2,-1.7$; Fig. 5, levels $-0.7,-1.7)$. These fibers were primarily ipsilateral to the injections, but a few were contralateral. Occasionally they could be seen to cross the midline in a transverse section. Fibers and varicosities could be found in this region apposed to retrogradely labeled neurons (Fig. $8 K$ ). Retrogradely labeled neurons in this region were contralateral to the injections of Fluoro-Gold, in contrast to those in the ventrally adjacent nucleus of the solitary tract, which were ipsilateral to the injections. Feldman and Kruger (1980) have previously observed cells retrogradely labeled from the ipsilateral thalamus in the nucleus of the solitary tract.

After cervical injections, labeled fibers were commonly seen in the reticular formation immediately ventral and ventrolateral to the cuneate nucleus, often spreading widely in the reticular formation. Sparse labeling in this area was also seen after lumbar injections. After cervical injections, some labeled fibers were seen in the rostral part of the spinal trigeminal nucleus, immediately medial to the spinal trigeminal tract.

\section{Rostral DCn}

The medial part of the rostral DCn was also labeled after injections at several levels of the spinal cord. This region, too, contained some labeled fibers after injections into all but sacral levels of the cord. Both in transverse (Fig. 3, levels +1.0, +1.3; Fig. 5, level +1.1 ) and horizontal (Figs. 4, $A-D ; 6$ ) sections, fibers were consistently labeled after injections into mid-thoracic or lumbar cord coursing rostrally from the main part of the gracile nucleus along the medial edge of the cuneate nucleus. Lumbar afferent fibers have previously been described in cats in the medial part of the rostral cuneate nucleus (primary afferent fibers: Hand, 1966; postsynaptic afferent fibers: Rustioni, 1973). After cervical and thoracic injections, but not after lumbar injections, labeled fibers extended into the external cuneate nucleus (Figs. 3, 6, 7).

\section{Lateral cervical nucleus}

Labeled fibers and varicosities were seen in the ipsilateral lateral cervical nucleus ( $\mathrm{LCn}$ ) after injections in cervical, thoracic, and lumbar cord. Especially in horizontal sections, these elements could be seen in apposition to neurons in the LCn that were retrogradely labeled with Fluoro-Gold (Fig. $8 L$ ). Spinocervical tract axons have not been previously observed directly apposed to retrogradely labeled lemniscal neurons in the LCn.

We observed no clear difference in the mediolateral distribution of afferents to the LCn from various segmental levels of 

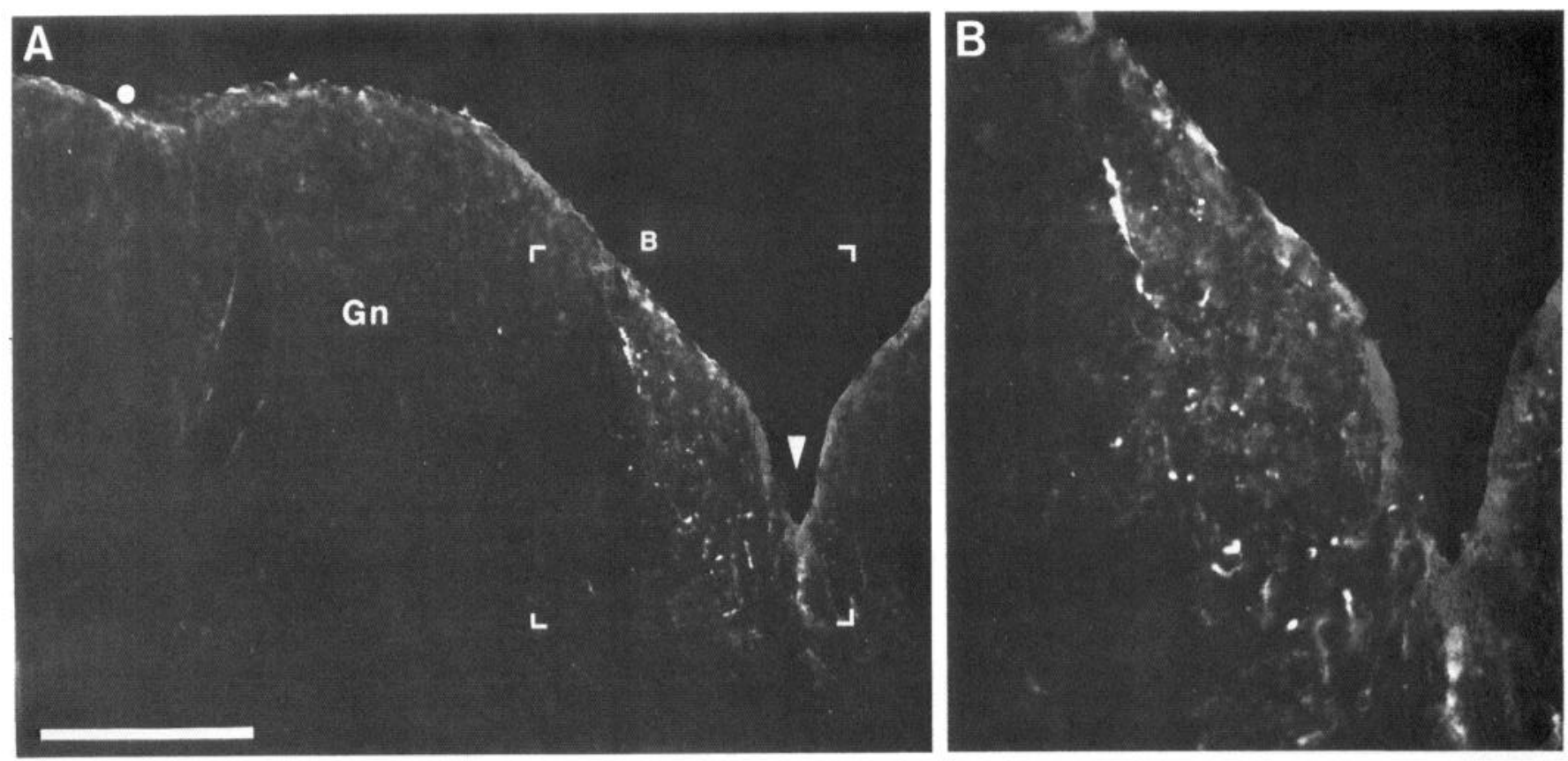

Figure 10. Photomicrographs of labeled fibers in a transverse section of the gracile nucleus at the level of the obex following injection of PHA-L in sacral spinal cord. $B$ is a higher power photomicrograph of the area designated in $A$. Note medial position of labeled fibers. Some bright edge artifact has been retouched. Dot, Dorsal intermediate sulcus at lateral edge of gracile nucleus. Arrowhead, Midline; Gn, gracile nucleus. Scale bar, $225 \mu \mathrm{m}(A) ; 113 \mu \mathrm{m}(B)$.

the spinal cord. This finding confirms the results from a study with degeneration techniques of the termination of the spinocervical tract in the rat (Giesler et al., 1988) and is consistent with the finding that many neurons throughout the LCn of rats have receptive fields that cover most or all of the body surface (Giesler et al., 1979b).

\section{Discussion}

\section{Technical considerations}

A large number of fibers and terminals were labeled in the dorsal column nuclei following our injections of PHA-L into the dorsal horn of the spinal cord. In addition to PSDC fibers, one or more of the following types of fibers may have been inadvertently labeled. (1) Primary afferent fibers passing through the injection site could have incorporated and transported PHA-L. Such labeling was probably not an important problem in this study. Other investigators have failed to find substantial labeling of axons of passage with PHA-L (Gerfen and Sawchenko, 1984; Grove et al., 1986). Also, we directly examined the ability of axons in the dorsal columns to transport PHA-L (Cliffer and Giesler, 1988). In approximately half of the cases, we failed to find labeling in the DCn after injections of PHA-L into the dorsal columns. In the other cases, only a few fibers were weakly labeled. The quality of the labeling clearly differed from that reported here. (2) Primary afferent axons could have been labeled via terminating collateral branches in the dorsal horn. This possibility also appears to be unlikely since we did not see labeled axons or cell bodies in the DRGs. (3) Cell bodies in other regions of the brain and spinal cord that project to the DCn might have been retrogradely labeled and then anterogradely transported PHA-L to the DCn. This possibility is also unlikely since we searched widely for labeled cell bodies and did not find any outside the vicinity of the injections. (4) PHA-L could have been transported transsynaptically from axons of spinal origin to neurons in the brain that projected to the DCn. This is also unlikely since we did not find any labeled postsynaptic cell bodies, even in areas of intense terminal labeling. Therefore, we conclude that the axonal labeling we observed in the DCn was due overwhelmingly to labeling of postsynaptic afferent fibers originating in or near the injections in the spinal cord.

All fibers labeled by injection of B-HRP into the DRGs were probably primary afferent fibers, not postsynaptic fibers labeled as a result of transsynaptic transport. We, like Robertson and Grant (1985), failed to observed labeled cells in the dorsal horn following injection of B-HRP into DRGs, even among dense accumulations of labeled fibers. In contrast, wheat germ agglutinin-conjugated HRP (WGA-HRP), for which evidence of transsynaptic transport exists, can be observed within cell bodies postsynaptic to stained fibers (Robertson and Grant, 1985; Peschanski and Ralston, 1985). Also, if transsynaptic transport of B-HRP had occurred in the dorsal horn, one would expect to find labeling in regions such as the brain-stem reticular formation which receives a large projection from dorsal horn neurons. No such labeling was evident in our tissue.

The cells retrogradely labeled with FG may belong to more than one subpopulation of lemniscal cells. The injections were mainly within the ventrobasal complex of the thalamus (VBC), but spread to the pretectum and the ventro-lateral midbrain, as well as to the zona incerta. In the cat, populations of cells in the DCn that project to the VBC appear to be different from those that project to the tectum, to the pretectum, or to the zona incerta (Blomqvist et al., 1978; Berkley et al., 1980, 1986; Bull and Berkley, 1984; Wiberg and Blomqvist, 1984). No such disjunction of populations of lemniscal cells has been shown in rats, and several studies have indicated that cells projecting to the thalamus in rats are distributed more uniformly throughout the DCn (Lund and Webster, 1967a; Tan and Lieberman, 1978; 

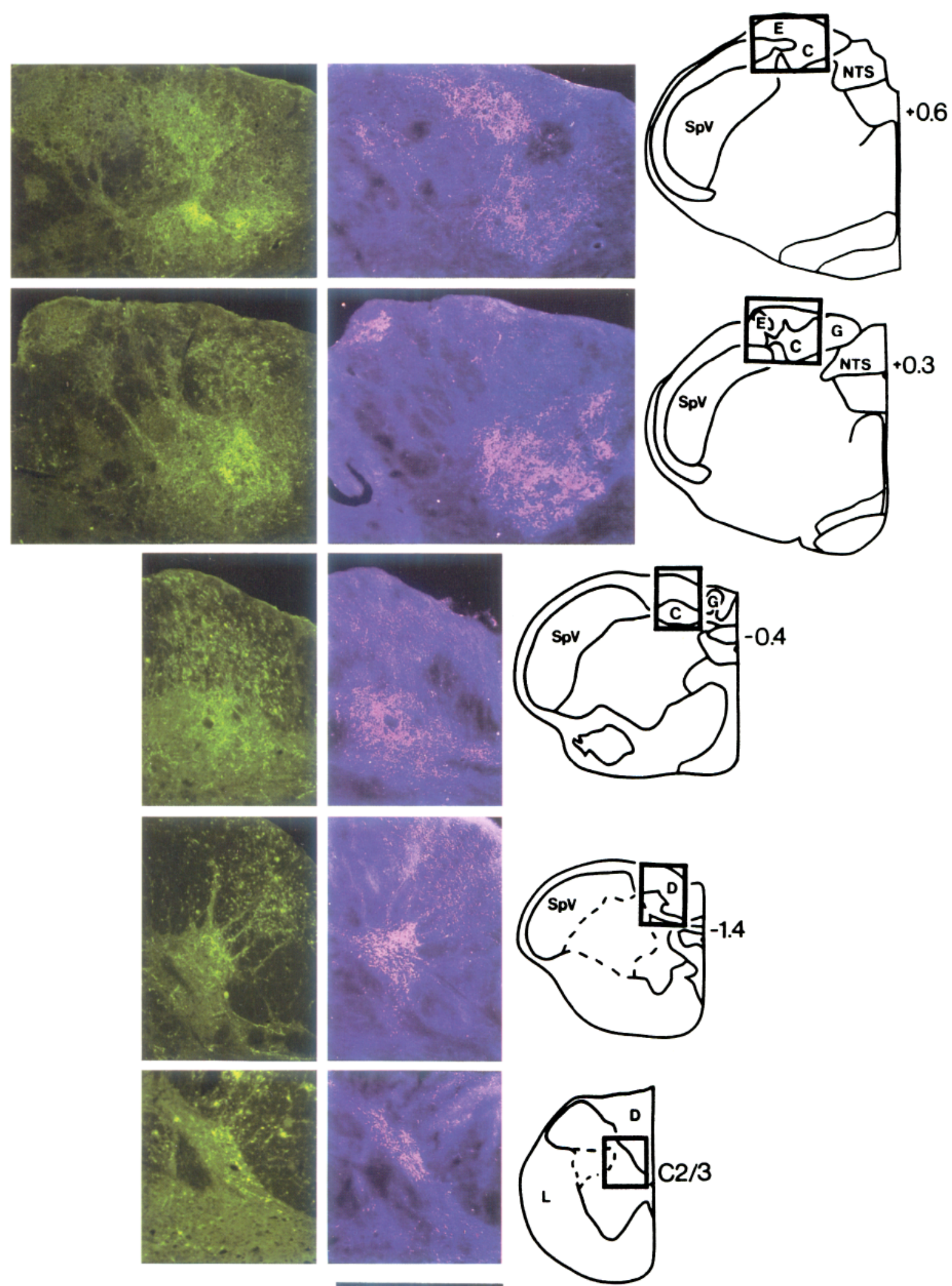

Figure 11. Pairs of photomicrographs of adjacent sections labeled for PHA-L (left) and HRP (right) after 8 injections of PHA-L in 2 transverse planes about $0.6 \mathrm{~mm}$ apart and injection of B-HRP into the DRG in segment C8. Drawings at right show locations of the photomicrographs, with approximate distance from the obex indicated in millimeters (calculated from numbers and thicknesses of sections; positive is rostral). Abbreviations as in Figure 8. Scale bar, $0.5 \mathrm{~mm}$. 

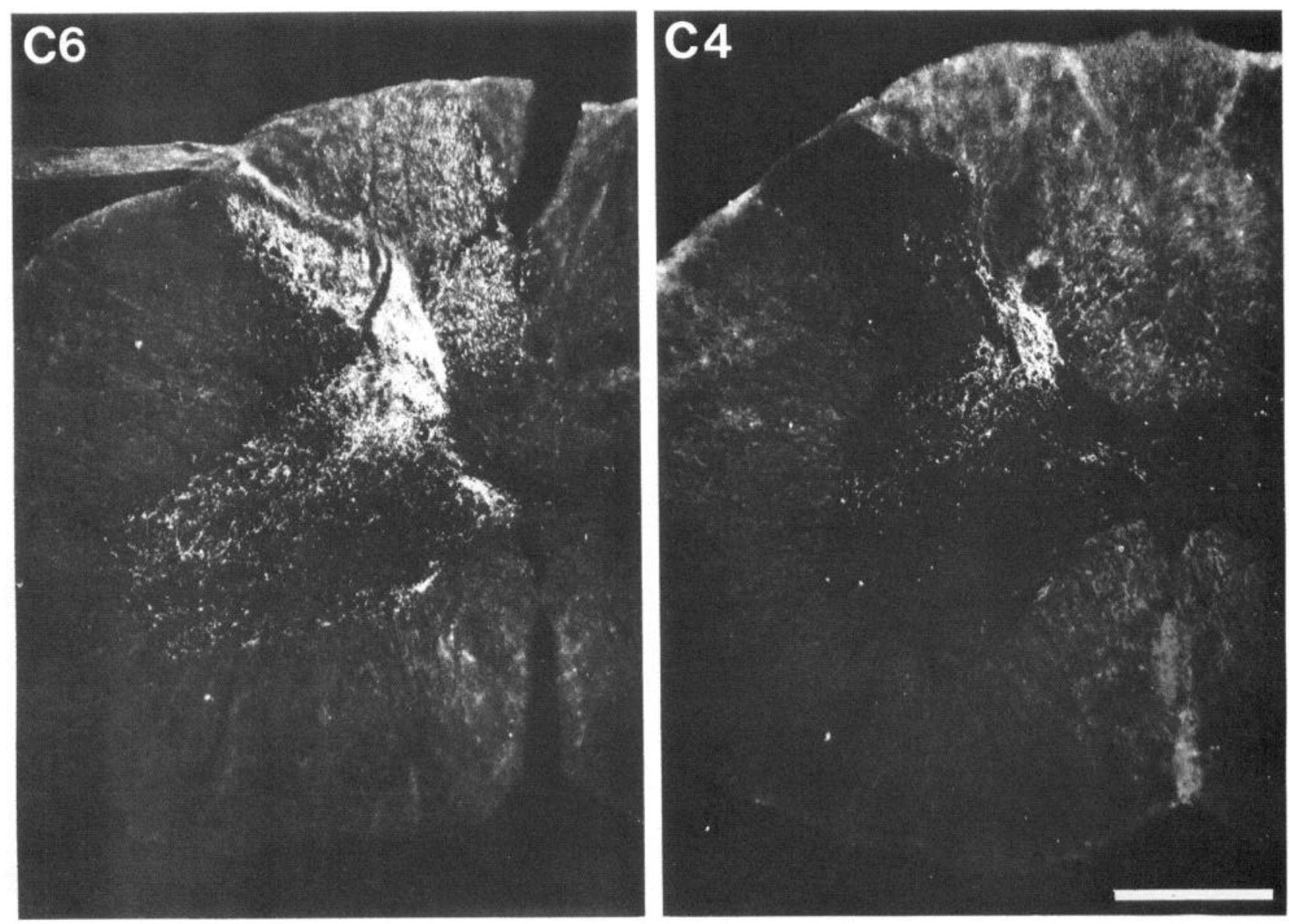

Figure 12. Photomicrographs of labeling in transverse sections through levels C6 and C4 after injection of B-HRP into DRGs of segments C7 and $\mathrm{C} 8$. Scale bar, $0.5 \mathrm{~mm}$.

Feldman and Kruger, 1980; Massopust et al., 1985). The pretectum and zona incerta receive projections only from rostral portions of the DCn (Lund and Webster, 1967a). However, it is not known whether single cells in the DCn of rats project exclusively to the pretectum or zona incerta. If so, some such cells may have been retrogradely labeled in our experiments.

\section{Distribution of PSDC fibers}

Although we did not examine the issue directly in the present study, it is likely that almost all of the labeled fibers within the dorsal column nuclei ascended to the medulla within the dorsal columns. We previously found that retrograde labeling of spinal cord neurons following injections of HRP into the gracile nucleus was completely blocked by restricted lesions of the dorsal columns (Giesler et al., 1984). We also found that dorsal column lesions prevented the labeling of more than $90 \%$ of the neurons that project to the cuneate nucleus. A small number of axons was found to project to the cuneate nucleus in the dorsal lateral funiculus (Giesler et al., 1984).

The postsynaptic projection to the dorsal column nuclei was found to be somatotopically organized. Injections of PHA-L into the cervical enlargement labeled fibers throughout most of the cuneate nucleus. Injections into thoracic cord labeled fibers in the medial cuneate and lateral gracile nuclei. Injections into the lumbar enlargement labeled fibers throughout most of the gracile nucleus. Injections in the sacral cord labeled fibers in the most medial part of the gracile nucleus. These results confirm our previous description of the somatotopic organization of the PSDC projection in rats that was based on retrograde tracing (Giesler et al., 1984). In addition, the present findings indicate that the organization of the PSDC system in rats is very similar to that of primary afferent projections in rats (Ranson et al., 1932; Basbaum and Hand, 1973; Beck, 1981; Imamura et al., 1986; Pfaller and Arvidsson, 1988), and of primary (Carpenter et al., 1968; Shriver et al., 1968; Wild, 1985; additional references in Norton and Kruger, 1973) and postynaptic (Rustioni, 1973, 1974; Rustioni et al., 1979) afferent projections in other species. Physiological mapping has shown that the neurons of the DCn are similarly organized (Norton and Kruger, 1973; Dykes et al., 1982).

The collective wide distribution of postsynaptic fibers throughout the DCn in rats contrasts sharply with the distribution that has been described for the cat. Taken together, cases in which we injected only very restricted regions of the spinal cord at sacral, lumbar, thoracic, or cervical levels contained labeled fibers throughout the DCn ipsilateral to the injections (Figs. 5, 7). In contrast, in cats cells in the lumbar and cervical spinal cord have been reported to project sparsely (Pierce et al., 1983; Pierce and Rustioni, 1985) or not at all (Rustioni, 1973, 1974) to large portions of the DCn. The areas in the DCn of cats that do not receive a projection from PSDC fibers are the cluster regions, the areas that contain the highest concentrations 
of neurons that project to the ventrobasal complex (Berkley, 1975; Cheek et al., 1975; Blomqvist and Westman, 1975; Blomqvist, 1980; Bull and Berkley, 1984). Therefore, in cats relatively little information transmitted by the PSDC pathway appears to be carried directly to neurons that project to the thalamus. In contrast, our results show postsynaptic afferent input to the DCn in the rat in all areas with high densities of medial lemniscal neurons. In addition, although we were able to see only the most proximal dendrites of labeled neurons, labeled fibers and varicosities were observed closely apposed to lemniscal neurons in all areas of the DCn. In fact, our results probably underrepresent the richness of the direct projection of PSDC afferent fibers to medial lemniscal neurons. In rats, ascending afferent fibers make synaptic contact almost exclusively on the dendrites of lemniscal neurons (Valverde, 1966; Walberg, 1966).

In the cat, areas appearing devoid of postsynaptic input have been observed to receive the heaviest input from primary afferent fibers (Hand, 1966; Rustioni and Macchi, 1968; Keller and Hand, 1970). In contrast, our results in the rat indicate extensive overlap of input from both postsynaptic and primary afferent fibers. This overlap is striking even in regions where primary afferent fibers are most heavily concentrated (Figs. 7, 8,11 , and Basbaum and Hand, 1973). We have observed retrogradely labeled lemniscal neurons split between sections that appeared to be contacted by both types of afferent fibers (unpublished observations). These observations suggest that individual lemniscal neurons in rats may receive input from both primary and postsynaptic afferent fibers.

In monkeys, the distribution of PSDC fibers in the gracile nucleus appears to differ from that in the cuneate nucleus. PSDC input is substantial throughout the gracile nucleus (Rustioni et al., 1979), resembling in this respect the distribution of PSDC fibers in rats. In contrast, the cuneate nucleus in monkeys, like that in cats, contains an area that appears devoid of heavy postsynaptic afferent input (Rustioni et al., 1979). It will be interesting to determine the relationship of these patterns to the locations of nociceptive neurons in the DCn of monkeys (Ferrington et al., 1988).

\section{Variations on somatotopy}

Injections of PHA-L into widely separated segmental levels each labeled fibers in restricted regions of the DCn. These included the ventral part of the gracile nucleus caudal to the obex and an area in the medial rostral DCn. These overlapping projections may be associated with the relatively large receptive fields that have been encountered in the rostral and caudal portions of the DCn in rats (McComas, 1963) and cats (Gordon and Paine, 1960; Gordon and Jukes, 1964).

Villaneuva et al. (1988) recorded nociceptive cells with wholebody receptive fields in the dorsal medullary reticular formation immediately ventral to the cuneate nucleus in rats. Their findings indicate that individual neurons in this region also receive input that originates in widespread regions of the body. After injections of PHA-L into cervical or lumbar cord, we observed labeling in the same area. Lima and Coimbra (1985, and personal communication) have injected the same area with retrograde tracers and observed labeled cells in the marginal zone of the cervical and lumbar enlargements. This labeling does not appear to be due to spread of the tracer into the DCn since no neurons were labeled in the marginal zone following injections of retrograde tracer that were restricted to the dorsally adjacent
DCn (Giesler et al., 1984). The labeling of marginal zone neurons seen following injections into the dorsal medullary reticular formation was blocked by lesions of the lateral part of the dorsal column (D. Lima, J. M. Castro-Lopes and A. Coimbra, personal communication). Thus, nociceptive cells in the marginal zone may contribute input, possibly through the dorsal columns, to nociceptive cells ventrally adjacent to the DCn.

Occasional fibers were labeled with PHA-L contralateral to our injections or in the ipsilateral non-homotopic nucleus (gracile from cervical or cuneate from lumbar). We do not think that such labeling was artifactual. As discussed above, fibers of passage were probably not labeled in substantial numbers. Furthermore, the locations of the injections were incompatible with non-homotopic labeling through fibers of passage. Injections in cervical cord were far from the gracile fasciculus, where fibers from lumbar levels pass (Giesler et al., 1984). Lumbar injections were centimeters caudal to ascending cervical fibers. The unilateral nature of the injections and scarcity of retrogradely labeled cells contralateral to the injections suggest that the contralateral labeling was due to contralaterally projecting cells. These findings confirm an earlier study in which retrograde tracers were used (Giesler et al., 1984). In that study, unilateral injections of HRP in the DCn labeled small numbers of neurons in the contralateral dorsal horn and in the non-homotopic part of the spinal cord. Others have noted similar occasional apparent departures from the somatotopic arrangement for primary afferent fibers in the DCn of rats (Ueyama et al., 1985), and for primary (Hand, 1966; Rustioni and Macchi, 1968; Keller and Hand, 1970; Kuo and de Groat, 1985; Wild, 1985) and postsynaptic (Rustioni, 1973, 1974; Rustioni et al., 1979) afferent fibers in other species.

\section{Internal basilar nucleus}

The IBn was described by Ramón y Cajal (1909) and Torvik (1956) as located in the ventromedial dorsal horn of upper cervical spinal cord. The IBn receives input from several sources. In the present study, injections of B-HRP into DRGs of the cervical enlargement labeled many primary afferent fibers within the IBn throughout the length of the cervical cord. Others havc also presented evidence for primary afferent input to the region of the IBn extending throughout the cervical spinal cord in rats (Webster and Kemplay, 1987) and monkeys (Shriver et al., 1968). The IBn also appears to receive projections from somatosensory cortex in cats (Armand et al., 1985) and rats (Zimmerman et al., 1964; Brown, 1971; Antal, 1984). The present studies have shown that postsynaptic afferent fibers from the cervical enlargement also project to the IBn.

The output of the IBn is not well understood. A large number of neurons in the IBn in segments $\mathrm{C} 1-2$ project to the ventrobasal thalamus (Giesler et al., 1979a; Granum, 1986; Kemplay and Webster, 1986). The projections of cells in the IBn in more caudal cervical segments are not known. It is also not known whether neurons in the rostral IBn have projections to areas other than the VBC.

The functional characteristics of neurons in the IBn have not been specifically investigated. Therefore, although the internal basilar nucleus receives a massive direct input from both primary and postsynaptic afferent fibers, stretching from the cervical enlargement to the medulla, the response characteristics of its neurons and the full range of their connections are not known. 


\section{References}

Angaut-Petit, D. (1975a) The dorsal column system: I. Existence of long ascending postsynaptic fibres in the cat's fasciculus gracilis. Exp. Brain Res. 22: 457-470.

Angaut-Petit, D. (1975b) The dorsal column system: II. Functional properties and bulbar relay of the postsynaptic fibres of the cat's fasciculus gracilis. Exp. Brain Res. 22: 471-493.

Antal, M. (1984) Termination areas of corticobulbar and corticospinal fibres in the rat. J. Hirnforsch. 25: 647-659.

Armand, J., G. Holstege, and H. G. J. M. Kuypers (1985) Differential corticospinal projections in the cat. An autoradiographic tracing study. Brain Res. 343: 351-355.

Basbaum, A. I., and P. J. Hand (1973) Projections of cervicothoracic dorsal roots to the cuneate nucleus of the rat, with observations on cellular "bricks." J. Comp. Neurol. 148: 347-360.

Beck, C. H. M. (1981) Mapping of forelimb afferents to the cuneate nuclei of the rat. Brain Res. Bull. 6: 503-516.

Bennett, G. J., Z. Seltzer, G.-W. Lu, N. Nishikawa, and R. Dubner (1983) The cells of origin of the dorsal column postsynaptic projection in the lumbosacral enlargements of cats and monkeys. Somatosens. Res. $1: 131-149$.

Bennett, G. J., N. Nishikawa, G.-W., Lu, M. J. Hoffert, and R. Dubner (1984) The morphology of dorsal column postsynaptic spinomedullary neurons in the cat. J. Comp. Neurol. 224: 568-578.

Berkley, K. J. (1975) Different targets of different neurons in nucleus gracilis of the cat. J. Comp. Neurol. 163: 285-304.

Berkley, K. J., A. Blomqvist, A. Pelt, and R. Flink (1980) Differences in the collateralization of neuronal projections from the dorsal column nuclei and lateral cervical nucleus to the thalamus and tectum in the cat: An anatomical study using two different double-labeling techniques. Brain Res. 202: 273-290.

Berkley, K. J., R. J. Budell, A. Blomqvist, and M. Bull (1986) Output systems of the dorsal column nuclei in the cat. Brain Res. Rev. 11: 199-225.

Berod, A., B. K. Hartman, and J. F. Pujol (1981) Importance of fixation in immunohistochemistry: Use of formaldehyde at variable $\mathrm{pH}$ for the localization of tyrosine hydroxylase. J. Histochem. Cytochem. 29: 844-850.

Blomqvist, A. (1980) Gracilo-diencephalic relay cells: A quantitative study in the cat using retrograde transport of horseradish peroxidase. J. Comp. Neurol. 193: 1097-1125.

Blomqvist, A., and J. Westman (1975) Combined HRP and FinkHeimer staining applied on the gracile nucleus in the cat. Brain Res. 99: 339-342.

Blomqvist, A., R. Flink, D. Bowsher, S. Griph, and J. Westman (1978) Tectal and thalamic projections of dorsal column and lateral cervical nuclei: A quantitative study in the cat. Brain Res. 141: 335-341.

Brown, L. T., Jr. (1971) Projections and termination of the corticospinal tract in rodents. Exp. Brain Res. 13: 432-450.

Bull, M. S., and K. J. Berkley (1984) Differences in the neurons that project from the dorsal column nuclei to the diencephalon, pretectum, and tectum in the cat. Somatosens. Res. 1: 281-300.

Carpenter, M. B., B. M. Stein, and J. E. Shriver (1968) Central projections of spinal dorsal roots in the monkey. II. Lower thoracic, lumbosacral and coccygeal dorsal roots. Am. J. Anat. 123: 75-118.

Cheek, M. D., A. Rustioni, and D. L. Trevino (1975) Dorsal column nuclei projections to the cerebellar cortex in cats as revealed by the use of the retrograde transport of horseradish peroxidase. J. Comp. Neurol. 164: 31-46.

Cliffer, K. D., and G. J. Giesler, Jr. (1988) PHA-L can be transported anterogradely through fibers of passage. Brain Res. 458: 185-191.

Dart, A. M., and G. Gordon (1973) Some properties of spinal connections of the cat's dorsal column nuclei which do not involve the dorsal columns. Brain Res. 58: 61-68.

Dykes, R. W., D. D. Rasmusson, D. Sretavan, and N. B. Rehman (1982) Submodality segregation and receptive-field sequences in cuneate, gracile, and external cuneate nuclei of the cat. J. Neurophysiol. 47: 389-416.

Feldman, S. G., and L. Kruger (1980) An axonal transport study of the ascending projection of medial lemniscal neurons in the rat. $\mathrm{J}$. Comp. Neurol. 192: 427-454.

Ferrington, D. G., J. W. Downie, and W. D. Willis (1988) Primate nucleus gracilis neurons: Responses to innocuous and noxious stimuli. J. Neurophysiol. 59: 886-907.

Gerfen, C. R., and P. E. Sawchenko (1984) An anterograde neuroan- atomical tracing method that shows the detailed morphology of neurons, their axons and terminals: Immunohistochemical localization of an axonally transported plant lectin, Phaseolus vulgaris leucoagglutinin (PHA-I). Brain Res. 290: 219-238.

Gibson, A. R., D. I. Hansma, J. C. Houk, and F. R. Robinson (1984) A sensitive low artifact TMB procedure for the demonstration of WG $\Lambda$-HRP in the CNS. Brain Res. 298: 235-241.

Giesler, G. J., Jr., and K. D. Cliffer (1985) Postsynaptic dorsal column pathway of the rat. II. Evidence against an important role in nociception. Brain Res. 326: 347-356.

Giesler, G. J., Jr., D. Menetrey, and A. I. Basbaum (1979a) Differential origins of spinothalamic tract projections to medial and lateral thalamus in the rat. J. Comp. Neurol. 184: 107-126.

Giesler, G. J., Jr., G. Urca, J. T. Cannon, and J. C. Liebeskind (1979b) Response properties of neurons of the lateral cervical nucleus in the rat. J. Comp. Neurol. 186: 65-78.

Giesler, G. J., Jr., R. L. Nahin, and A. M. Madsen (1984) Postsynaptic dorsal column pathway of the rat. I. Anatomical studies. J. Neurophysiol. 51: 260-275.

Giesler, G. J., Jr., M. Bjorkeland, Q. Xu, and G. Grant (1988) Organization of the spinocervicothalamic pathway in the rat. J. Comp. Neurol. 268: 223-233.

Gordon, G., and M. G. M. Jukes (1964) Dual organization of the exteroceptive components of the cal's gracile nucleus. J. Physiol. (Lond.) 173: 263-290.

Gordon, G., and C. H. Paine (1960) Functional organization in nucleus gracilis of the cat. J. Physiol. (Lond.) 153: 331-349.

Granum, S. L. (1986) The spinothalamic system of the rat. I. Locations of cells of origin. J. Comp. Neurol. 247: 159-180.

Grove, E. A., V. B. Domesick, and W. H. H. Nauta (1986) Light microscopic evidence of striatal input to intrapallidal neurons of cholinergic cell group Ch4 in the rat: A study employing the anterograde tracer Phaseolus vulgaris leucoagglutinin (PHA-L). Brain Res. 367: 379-384.

Hand, P. J. (1966) Lumbosacral dorsal root terminations in the nucleus gracilis of the cat. Some observations on terminal degeneration in other medullary sensory nuclei. J. Comp. Neurol. 126: 137-156.

Imamura, J., M. C. Saunders, and J. T. Keller (1986) Projections of cervical nerves to the rat medulla. Neurosci. Lett. 70: 46-51.

Kamogawa, H., and G. J. Bennett (1986) Dorsal column postsynaptic neurons in the cat are excited by myelinated nociceptors. Brain Res. 364: 386-390.

Keller, J. H., and P. J. Hand (1970) Dorsal root projections to nucleus cuneatus of the cat. Brain Res. 20: 1-17.

Kemplay, S. K., and K. E. Webster (1986) A qualitative and quantitative analysis of the distributions of cells in the spinal cord, and spinomedullary junction projecting to the thalamus of the rat. Neuroscience 17: 769-789.

Kuo, D. C., and W. C. de Groat (1985) Primary afferent projections of the major splanchnic nerve to the spinal cord and gracile nucleus of the cat. J. Comp. Neurol. 231: 421-434.

Lima, D., and A. Coimbra (1985) Marginal neurons of the rat spinal cord at the origin of a spinobulboreticular projection. Neurosci. Lett. (Suppl. 22): S9.

Lu, G.-W., G. J. Bennett, N. Nishikawa, M. J. Hoffert, and R. Dubner (1983) Extra- and intracellular recordings from dorsal column postsynaptic spinomedullary neurons in the cat. Exp. Neurol. 82: 456478.

Lund, R. D., and K. E. Webster (1967a) Thalamic afferents from the dorsal column nuclei. An experimental anatomical study in the rat. J. Comp. Neurol. 130: 301-312.

Lund, R. D., and K. E. Webster (1967b) Thalamic afferents from the spinal cord and trigeminal nuclei. An experimental anatomical study in the rat. J. Comp. Neurol. 130: 313-328.

Massopust, L. C., D. H. Hauge, J. C. Ferneding, W. G. Doubek, and J. J. Taylor (1985) Projection systems and terminal localization of dorsal column afferents: An autoradiographic and horseradish peroxidase study in the rat. J. Comp. Neurol. 237: 533-544.

McComas, A. J. (1963) Responses of the rat dorsal column system to mechanical stimulation of the hind paw. J. Physiol. (Lond.) 166:435448 .

Mesulam, M.-M. (1978) Tetramethyl benzidine for horseradish peroxidase neurochemistry: A non-carcinogenic blue reaction product with superior sensitivity for visualizing neural afferents and efferents. J. Histochem. Cytochem. 26: 106-117.

Norton, A. C., and L. Kruger (1973) The Dorsal Column System of 
the Spinal Cord: Its Anatomy, Physiology, Phylogeny and Sensory Function, 5th ed., Brain Information Service/Brain Research Institute, UCLA, Los Angeles.

Papez., J. W. (1929) Comparative Neurology. A Manual and Text for the Study of the Nervous System of Vertebrates, Thomas Y. Crowell, New York.

Peschanski, M., and H. J. Ralston III (1985) Light and electron microscopic evidence of transneuronal labeling with WGA-HRP to trace somatosensory pathways to the thalamus. J. Comp. Neurol. 236: 2941.

Petit, D. (1972). Postsynaptic fibres in the dorsal columns and their relay in the nucleus gracilis. Brain Res. 48: 380-384.

Pfaller, K., and J. Arvidsson (1988) Central distribution of trigeminal and upper cervical primary afferents in the rat studied by anterograde transport of horseradish peroxidase conjugated to wheat germ agglutinin. J. Comp. Neurol. 268: 91-108.

Pierce, J., and A. Rustioni (1985) Post-synaptic afferent terminations in the cat dorsal column nuclei visualized by PHA-L bean lectin. Soc. Neurosci. Abstr. 11: 560.

Pierce, J., A. Rustioni, S. Cheema, and R. Fyffe (1983) Post-synaptic dorsal column fiber terminal patterns in the nucleus cuneatus of the cat. Soc. Neurosci. Abstr. 9: 246.

Ramón y Cajal, S. (1909) Histologie du Systeme Nerveux de l'Homme \& des Vertebres, Tome Premier. A. Maloine, Paris.

Ranson, S. W., H. K. Davenport, and E. A. Doles (1932) Intramedullary course of the dorsal root fibers of the first three cervical nerves. J. Comp. Neurol. 54: 1-12.

Robertson, B., and G. Grant (1985) A comparison between wheat germ agglutinin- and choleragenoid-horseradish peroxidase as anterogradely transported markers in central branches of primary sensory neurones in the rat with some observations in the cat. Neuroscience 14: 895-905.

Rustioni, A. (1973) Non-primary afferents to the nucleus gracilis from the lumbar cord of the cat. Brain Res. 51:81-95.

Rustioni, A. (1974) Non-primary afferents to the cuneate nucleus in the brachial dorsal funiculus of the cat. Brain Res. 75: 247-259.

Rustioni, A. (1976) Spinal neurons project to the dorsal column nuclei of rhesus monkeys. Science 196: 656-658.

Rustioni, A., and A. B. Kaufman (1977) Identification of cells of origin of non-primary afferents to the dorsal column nuclei of the cat. Exp. Brain Res. 27: 1-14.

Rustioni, A., and G. Macchi (1968) Distribution of dorsal root fibers in the medulla oblongata of the cat. J. Comp. Neurol. 134: 113-126.

Rustioni, A., N. L. Hayes, and S. O'Neill (1979) Dorsal column nuclei and ascending spinal afferents in macaques. Brain 102: 95-125.

Schmued, L. C., and J. H. Fallon (1986) Fluoro-Gold: A new fluorescent retrograde axonal tracer with numerous unique properties. Brain Res. 377: 147-154.

Schmued, L. C., L. W. Swanson, and P. E. Sawchenko (1982) Some fluorescent counterstains for neuroanatomical studies. J. Histochem. Cytochem. 30: 123-128.

Shriver, J. E., B. M. Stein, and M. B. Carpenter (1968) Central projections of spinal dorsal roots in the monkey. I. Cervical and upper thoracic dorsal roots. Am. J. Anat. 123: 27-74.

Tan, C. K., and A. R. Lieberman (1978) Identification of thalamic projection cells in the rat cuneate nucleus: $A$ light and electron microscopic study using horseradish peroxidase. Neurosci. Lett. 10:1922.

Torvik, A. (1956) Afferent connections to the sensory trigeminal nuclei, the nucleus of the solitary tract and adjacent structures. An experimental study in the rat. J. Comp. Neurol. 106: 51-141.

Uddenberg, N. (1966) Studies on modality segregation and secondorder neurones in the dorsal funiculus. Experientia 22: 441-442.

Uddenberg, N. (1968a) Differential localization in dorsal funiculus of fibres originating from different receptors. Exp. Brain Res. 4: 367376.

Uddenberg, N. (1968b) Functional organization of long, second-order afferents in the dorsal funiculus. Exp. Brain Res. 4: 377-382.

Ueyama, T., H. Arakawa, and N. Mizuno (1985) Contralateral termination of pudendal nerve fibers in the gracile nucleus of the rat. Neurosci. Lett. 62: 113-117.

Valverde, F. (1966) The pyramidal tract in rodents. A study of its relations with the posterior column nuclei, dorsolateral reticular formation of the medulla oblongata, and cervical spinal cord (Golgi and electron microscopic obervations). Zeitschr. f. Zellforsch. 71: 297363.

Villanueva, L., D. Bouhassira, Z. Bing, and D. Le Bars (1988) Convergence of heterotopic nociceptive information onto subnucleus reticularis dorsalis neurons in the rat medulla. J. Neurophysiol. 60: 980-1009.

Walberg, F. (1966) The fine structure of the cuneate nucleus in normal cats and following interruption of afferent fibres. An electron microscopical study with particular reference to findings made in Glees and Nauta sections. Exp. Brain Res. 2: 107-128.

Webster, K. E., and S. K. Kemplay (1987) Distribution of primary afferent fibres from the forelimb of the rat to the upper cervical spinal cord in relation to the location of spinothalamic neuron populations. Neurosci. Lett. 76: 18-24.

Wiberg, M., and A. Blomqvist (1984) The projection to the mesencephalon from the dorsal column nuclei. An anatomical study in the cat. Brain Res. 311: 225-244.

Wild, J. M. (1985) The avian somatosensory system. I. Primary spinal afferent input to the spinal cord and brainstem in the pigeon (Columba livia). J. Comp. Neurol. 240: 377-395.

Zimmerman, E. A., W. W. Chambers, and C. N. Liu (1964) An experimental study of the anatomical organization of the cortico-bulbar system in the albino rat. J. Comp. Neurol. 123: 301-324. 